Article

\title{
Investigation of Black-Starting and Islanding Capabilities of a Battery Energy Storage System Supplying a Microgrid Consisting of Wind Turbines, Impedance- and Motor-Loads
}

\author{
Jürgen Marchgraber *(D) and Wolfgang Gawlik \\ Institute of Energy Systems and Electrical Drives, TU Wien, 1040 Vienna, Austria; gawlik@ea.tuwien.ac.at \\ * Correspondence: marchgraber@ea.tuwien.ac.at
}

Received: 30 August 2020; Accepted: 22 September 2020; Published: 5 October 2020

\begin{abstract}
Microgrids are small scale electrical power systems that comprise distributed energy resources (DER), loads, and storage devices. The integration of DER into the electrical power system basically allows the clustering of small parts of the main grid into Microgrids. Due to the increasing amount of renewable energy, which is integrated into the main grid, high power fluctuations are expected to become common in the next years. This carries the risk of blackouts to be also more likely in the future. Microgrids hold the potential of increasing reliability of supply, since they are capable of providing a backup supply during a blackout of the main grid. This paper investigates the black-starting and islanding capabilities of a battery energy storage system (BESS) in order to provide a possible backup supply for a small part of the main grid. Based on field tests in a real Microgrid, the backup supply of a residential medium voltage grid is tested. Whereas local wind turbines within this grid section are integrated into this Microgrid during the field test, the supply of households is reproduced by artificial loads consisting of impedance- and motor loads, since a supply of real households carries a high risk of safety issues and open questions regarding legal responsibility. To operate other DER during the island operation of such a Microgrid, control mechanisms have to ensure the power capabilities and energy reserves of the BESS to be respected. Since the operation during a backup supply of such a Microgrid requires a simple implementation, this paper presents a simple master-slave control approach, which influences the power output of other DER based on frequency characteristics without the need for further communication. Besides the operation of other DER, the capability to handle load changes during island operation while ensuring acceptable power quality is crucial for such a Microgrid. With the help of artificial loads, significant load changes of the residential grid section are reproduced and their influence on power quality is investigated during the field tests. Besides these load changes, the implementation and behavior of the master-slave control approach presented in this paper is tested. To prepare these field tests, simulations in MATLAB / SIMULINK are performed to select appropriate sizes for the artificial loads and to estimate the expected behavior during the field tests. The field tests prove that a backup supply of a grid section during a blackout of the main grid by a BESS is possible. By creating the possibility of operating other DER during this backup supply, based on the master-slave control approach presented in this paper, the maximum duration for this backup supply can be increased.
\end{abstract}

Keywords: microgrid; black-start; islanding; master-slave control approach; cold load pickup

\section{Introduction}

In order to mitigate global warming, the integration of renewable energy will increase dramatically in the coming years. Several studies calculate a share of $50 \%$ of renewable energy in the power 
sector in 2030 [1,2]. A high percentage of this share will be covered by variable renewable energy, namely solar photovoltaic- and wind power systems. Due to the variable infeed-behavior of these technologies, severe power fluctuations of the total power infeed in the electric power grid are expected to become common. These power fluctuations lead to high differences between load and generation. The need for additional flexibilities in the power system to balance these differences, therefore, is indisputable. Storage technologies are one way to create additional flexibility. Long- and short-term storage technologies, therefore, are expected to be increasingly integrated in the power system [3]. Battery Energy Storage Systems (BESS) are expected to cover a part of the short-term storage demand for durations between minutes, hours or days. Examples of how the flexibility of BESS will be used to handle power fluctuations, for example, are the application of "peak-shaving" to avoid overload of transmission lines or their contribution to frequency control by providing frequency reserves. There are more of such examples, but they all have one property in common, which is that no continuous activation will take place. For example, peak-shaving may only be necessary in times of high stress of the grid, otherwise the surplus power may be transmitted to places of higher demand. The corresponding flexibility in the latter situation would be transmission of power, leading to the necessity of grid expansion, which is also listed as a requirement for flexibility in the future power system in several studies [1,2]. Because BESS are considered not to perform peak-shaving, frequency control, or other services, continuously, the idea of "value-stacking" arises. Other services or applications, which are not directly related to handle power fluctuations in the future power system, are considered as a way to increase the profitability of a BESS, by providing them besides other services. Islanding can be considered as one of such applications. Due to the high amount of renewable energy in the future power system, the risk of blackouts increases. By building local Microgrids and perform an island operation during such blackouts, the reliability of supply can be increased.

The increasing amount of decentralized energy resources (DER) offers the possibility to build such Microgrids (MG). According to Marney et al. [4], Microgrids comprise low voltage distribution systems with distributed energy sources, storage devices, and controllable loads, operated connected to the main power grid or islanded, in a controlled, coordinated way. According to Mahmoud et al. [5], there are several ways to to categorize MG, for example, by their application type (Utility MG, Commercial MG, Industrial MG, remote/off-grid MG), their system structure (single-stage/two-stage power-conversion systems), the type of control (centralized, decentralized or ditributed), etc. Based on the application type, the MG are embedded into the low- or medium-voltage level of the main grid, depending on the size of the integrated loads and DER. Remote MG are an exception, which are operating without any connection to the main grid. A Microgrid has two operation modes, which are termed as "grid-connected mode" and "island mode". The operation of a Microgrid separate from the main grid in island mode is based on suitable control algorithms. In the case of a blackout of the main grid, a Microgrid is able to switch from grid-connected mode to island mode, either via a black-start or by a smooth transition. Therefore, an appropriately designed Microgrid improves reliability and resiliency by providing a back-up system against grid faults [6]. There may also be an application for Microgrids to facilitate the restoration process after blackouts [7]. Besides such applications of Microgrids which are "embedded" into the main grid, the most straightforward application of Microgrids is their application in remote areas, where it is not possible or economically not feasible to provide a sufficient power link to the main grid, as, for example, described in [8].

Many DER are connected to the grid via converters. To be able to operate an islanded Microgrid, at least one of these DER must have island capabilities in order to control the voltage and frequency in the Microgrid. Such converters are called "grid-forming" converters. The major difference between grid-forming converters and conventional "grid-following" converters is their ability to build the grid angle on their own, whereas grid-following converters rely on the determination of the grid angle based on the voltage measurement at their point of common coupling (PCC). The supply of an islanded Microgrid by multiple grid-forming units requires the application of appropriate load sharing techniques. Conventionally, a voltage- and frequency droop control is adopted in such cases, 
as, for example, described by Katiraei and Iaravni [9] or by Barklund et al. [10]. However, conventional droop control neglects the influence of the coupling of the grid-forming units [11]. This results in large power circulating-currents and power fluctuations of the Microgrid [12]. Improved droop control strategies, as, for example, proposed by Peng et al. [11], are using virtual impedances in order to take into account the coupling of the grid-forming units. For the application of a Microgrid, to build a backup supply during the blackout of the main grid, as described above, the use of several grid-forming units may be not very practical, at least for smaller Microgrids. Most of the DER, which will be integrated into the main grid in the future are based on variable renewable generation. Therefore, they are not fully capable of contributing to power balancing during a backup supply in an islanded Microgrid because they are connected via grid-following converters and may only cover a share of the energy demand of the loads in an intermittent way. However, as described above, the integration of decentralized BESS nearby to larger DER based on variable renewable energy in the future is very likely in order to handle the power fluctuations of these DER. By designing such BESS to be able to switch between a grid-following and a grid-forming mode, this opens the possibility to build Microgrids of certain sections of the main grid. The most practicable approach for such an arrangement is a master-slave control approach. Such a master-slave approach is characterized by using only one grid-forming unit, which represents the "master" during island operation, while the other DER are acting as "slave" in a grid-following mode. This approach is usually also used when Microgrids are supplied with large diesel generators, for example as described in [13], but can also be used to achieve a sustainable supply of Microgrids based only on renewable energy. Although master-slave control approaches for Microgrids have already been investigated in several studies [13-16], the major drawbacks can be identified by the need for communication [14-16] and the lack of experimental investigations in real world grid sections, since all studies are limited to simulations. An example for real world measurements can be found in [13] where power quality measurements in an artificial test Microgrid were performed. However, Garde et al. [13] conclude the lack of energy management for the BESS, which acts as a master unit in their test Microgrid. This paper presents a master-slave approach without the need for communication and the possibility to perform a simple energy management of the BESS.

As already mentioned above, BESS are considered to become a necessity to provide flexibility in the future power system as short-term storages. Due to decreasing prices of Li-Ion battery cells [17], this technology is considered to make up the majority of BESS which are used in the future. Against the background of value-stacking, islanding is considered as an additional service BESS can provide to increase their profitability, while at the same time increasing the reliability of supply in the case of blackouts of the interconnected power grid by building local Microgrids. Assuming such Microgrids to comprise a high share of variable renewable energy, an easy approach for ensuring their functionality during island operation is desired in order to lower the requirements of the energy reserves of the BESS and to increase the maximum duration of island operation. This paper presents a master-slave approach based on a variable frequency, which allows the power infeed of variable renewable energy during island operation of a Microgrid, without the need for additional communication. Furthermore, the black-start and island operation of a real Microgrid is investigated, within which this master-slave approach is applied. This real Microgrid comprises a BESS, wind turbines, and loads, which are used to reflect the behavior of a residential grid section. The motivation for this paper is to investigate the possibility of black-starting and operating a residential grid section during an assumed blackout of the interconnected power grid that the residential network is connected with. Whereas the BESS and the wind turbines are integrated into the corresponding grid section during normal operation, the connection of the nearby residential grid section, comprising several households, was not possible due to safety reasons. Therefore, several impedance- and motor-loads are used to reproduce significant load-steps of this residential grid section. Via field tests, the black-starting and islanding capabilities of the Microgrid and the master-slave approach presented in this paper are investigated. For preparation 
of these field tests, simulations in MATLAB / SIMULINK were performed, which allowed an evaluation of the expected results.

To present the corresponding results and findings, this paper is structured as follows. Section 2 presents the simulation model used in the simulations and presents the simulation results of a black-start and during load-changes in island operation. Section 3 presents the measurement results which were taken during field tests in a real Microgrid. Section 4 concludes the paper.

This paper focuses on Microgrids that use a BESS as master unit in a master-slave control strategy described above. Related to these types of Microgrids, the following Section 1.2 discusses more details on the black-start of such Microgrids and Section 1.3 discusses more details on master-slave control approach which is investigated in this paper.

\subsection{Nomenclature}

To tell apart unit-based and normalized values, uppercase and lowercase letters are used. Uppercase letters are related to unit-based values, while lowercase letters are related to normalized values. Normalized values are using the unit "pu". To tell apart phasors and instantaneous values, the index " $\mathrm{t}$ " is used for instantaneous values. Bold symbols identify a vector. Nominal values are identified with the index " $n$ ". A list of all symbols used in this paper is summarized in Appendix A.

\subsection{Black-Start}

The black-start of a Microgrid defines the process of restoring it after a shutdown without any external voltage support. The operation of a Microgrid is often preceded by a black-start, which may be necessary in the case of a blackout of the main grid, when no smooth transition of the Microgrid from grid-connected into island mode takes place, or in case of a remote Microgrid, where a supply may only be given during specific time periods during the day. The black-start of a Microgrid is a challenging task to which special attention must be paid. The main issue with black-starting an island grid is a phenomenon which is termed as "cold load pickup". In particular, a high penetration of thermostatically controlled devices leads to a high power demand during the black-start of a Microgrid [18]. During normal operation, their activity is evenly distributed, whereas during a black-start all of these devices drain power at the same time, as the thermostatically controlled area got "cold" during the blackout. The same behavior occurs with many devices, as their random switching during normal operation may be lost during a black-start. In addition, their power consumption during start-up may be higher than during normal operation, for example, because of certain start-up routines. In addition, most types of loads drain power depending on the temperature. If they possess a negative temperature coefficient, their resistance decreases with rising temperature. Therefore, during a start-up process of a load where the load temperatures are lowest, they drain higher power than in their nominal operating point. The remaining equipment of a Microgrid, as for example transformers and cables, also have a higher power demand during start-up. The inrush currents of transformers and the initial charging process of the capacitances of cables are the main reasons for this higher power demand. The challenge of performing a black-start, therefore, is to handle the "cold load pickup" in terms of both active- and reactive power.

The most important property to perform a black-start is the black-start ability of at least one grid-forming unit in the Microgrid. Assuming a BESS to be this grid-forming unit, such a black-start ability can only be achieved if all of its components and control systems can be activated and maintained without any external power supply. The most common solution to reach such a condition is the use of an additional uninterruptible power source (UPS) to supply these components of the BESS. The primary battery of the BESS itself can also be an option to serve as a power supply. However, as some of the components are necessary to start-up and run the battery itself and the AC-output voltage of the BESS often differs from the voltage that is needed to supply all components and auxiliary systems (e.g., $400 \mathrm{~V}$ ), the use of an additional UPS is also a common approach. One of the biggest consumer of all necessary components to maintain a BESS is its heating, ventilation, and air conditioning (HVAC) 
system. Therefore, the UPS must be designed to handle such a power consumption or the BESS must be designed to start-up without an active HVAC system.

In general, black-start ability also requires the BESS to be operable automatically, remotely or by local staff. It has to be guaranteed that all breakers are functional without any external power supply in order to start-up the BESS and establish a connection to the Microgrid. A corresponding start-up routine has to guarantee a procedure to appropriately control these breakers in an intended sequence. A crucial point of such a start-up routine is an appropriate island detection. The island detection guarantees that a black-start and further connection to a Microgrid, by closing the relevant breaker at the PCC of the BESS, is only possible when the Microgrid is without voltage and not connected to the main grid. Otherwise, massive damage may be caused to the BESS and other components due to very high currents as a result of possible phase differences between the voltage of the BESS and the voltage of the main grid. Therefore, a synchronization unit is essential for a connection to the main grid. At the end of a start-up routine, the relevant breaker of the PCC is closed in order to energize the Microgrid. As already mentioned above, the BESS has to be capable of handling the cold load pickup that may arise during this process. A simple way to deal with the cold load pickup is to gradually increase the system voltage instead of performing a black-start with nominal voltage during this last step of connecting to the Microgrid. In addition, the inrush currents of all transformers and the charging currents of the cable capacitances in the island grid can be decreased by doing so. Although most of the electrical equipment and loads will not be damaged due to operation with under-voltage, there may be processes that rely on voltage magnitudes within certain limits. For loads that are part of such processes, a corresponding breaker logic has to guarantee that their connection is only established after a certain voltage limit has been reached. In addition, protection devices may have to be reconfigured to handle the gradual increase of the system voltage. In addition, the protection devices of the BESS that are configured to trip as a consequence of under-voltage have to be reconfigured.

\subsection{Island Operation}

The black-start of a Microgrid is followed by the island operation. The challenge during island operation is to manage the active- and reactive power demand that results from the load behavior, and the active- and reactive infeed that results from DER in the Microgrid. Therefore, an islanded Microgrid that contains several DER requires suitable control mechanisms to ensure that the maximum power of the grid-forming unit is respected. The implementation of such control mechanisms offers the possibility of operating an islanded Microgrid, the peak load, and the peak infeed that exceed the nominal power of its grid-forming unit. At least a part of the load can be supplied by DER while the grid-forming unit only has to deliver balancing power. The challenge of such an operation is the impact of a sudden imbalance between load and generation. The control mechanisms mentioned above have to ensure that such imbalances become controllable by the grid-forming unit.

The ability of grid-forming converters to generate the grid angle on their own offers the potential of dictating the frequency to actively influence the power output of other generating units and the power consumption of loads in an islanded Microgrid via pre-defined frequency characteristics.

The simplest approach for such control mechanisms is using load-shedding for a surplus of load and power reduction for a surplus of infeed, in case either of them exceeds the power limits of the grid-forming unit. The frequency in the Microgrid can be used as control signal for both operations without the need for additional communication. For load-shedding, additional breakers that trip at certain frequency limits and a stepwise load-shedding plan with prioritization of loads may be necessary. For power reduction of generation units, the "limited frequency sensitive mode" (LFSMO) can be used. According to latest grid codes [19], generation units have to reduce their power output in case of a frequency that exceeds a limit of $50.2 \mathrm{~Hz}$. This mechanism can be used in an islanded Microgrid to actively influence the power output of DER through the LFSMO. This kind of frequency control approach can not only be used to limit power flows beyond the limits of the BESS, but can also be used to perform an energy management to manage the state of charge $(\mathrm{SoC})$. Such a frequency 
control approach is already being used in home storage systems [20]. A corresponding frequency characteristic to be used in a Microgrid described above is shown in Figure 1.

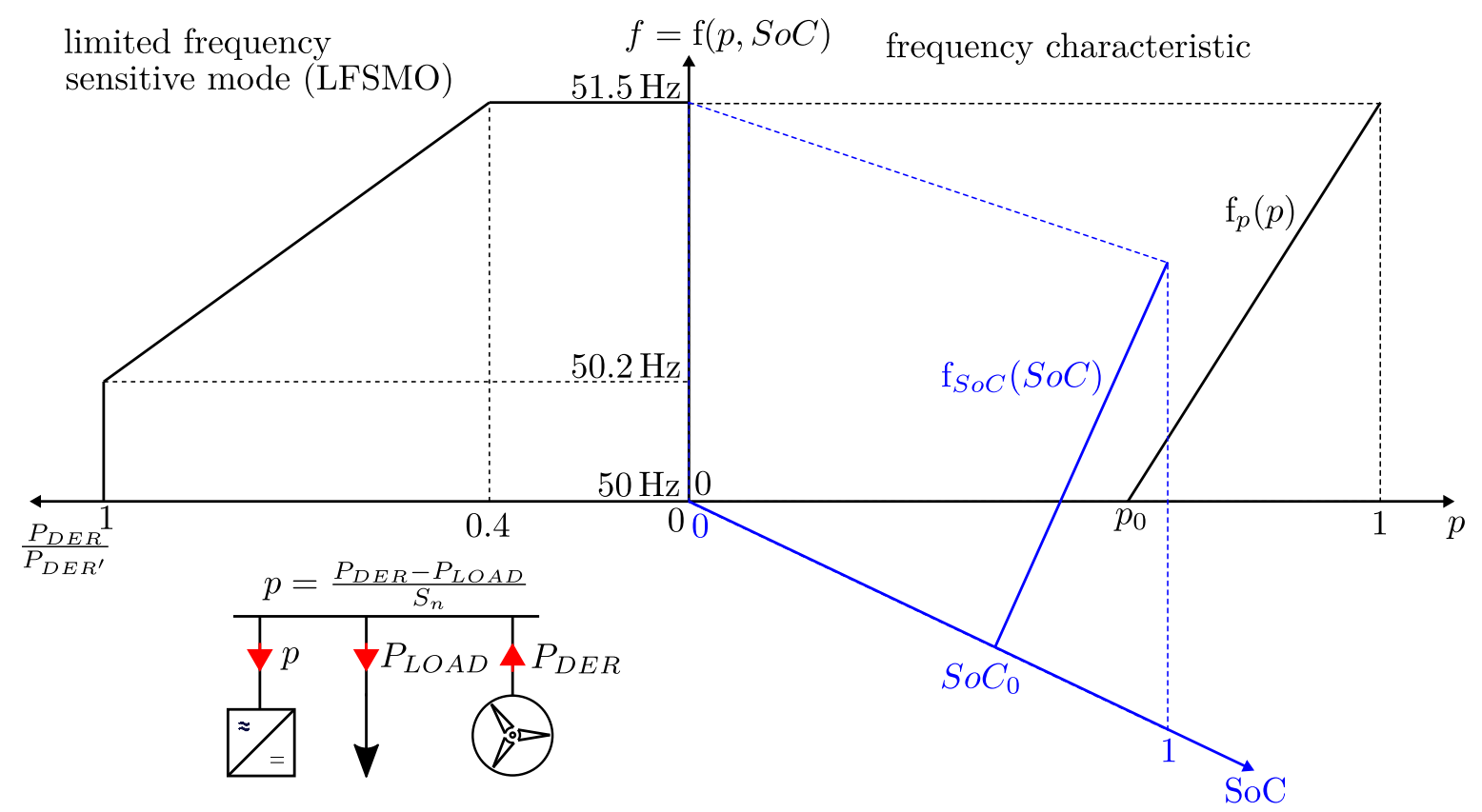

Figure 1. Characteristic to control the frequency of a grid-forming BESS in order to reduce the currently possible power output $P_{D E R}^{\prime}$ of other generating units to a reduced power output $P_{D E R}$ in case of a high SoC or in case the imbalance between generation and load $p$ reaches values near $100 \%$ (rated power of the BESS).

The normalized power intake of the grid-forming BESS is defined by $p=\frac{P_{D E R}-P_{L O A D}}{S_{n}}$ and equals the power imbalance between the power infeed of DER $P_{D E R}$ and the power consumption of loads $P_{L O A D}$ in the Microgrid, which is normalized to the nominal apparent power $S_{n}$ of the BESS. The values $p_{0}$ and $S_{o} C_{0}$ can be used to parameterize the frequency characteristic. The grid-forming BESS controls its output frequency according to the resulting frequency characteristic. As a consequence of the LFSMO, the DER starts to reduce their currently possible power output $P_{D E R}^{\prime}$ above a frequency of $50.2 \mathrm{~Hz}$ in $50 \mathrm{~Hz}$-systems to a reduced power output $P_{D E R}$. According to Figure 1 , the frequency $f$ of the BESS is a function of the normalized power intake $p$ and the state of charge $S o C$, defined by $f=\mathrm{f}(p, S o C)$. To deal with situations when $p>p_{0}$ and $S_{o} C>S_{o} C_{0}$, this function is defined by

$$
f=\mathrm{f}(p, S o C)=\max \left[\mathrm{f}_{p}(p), \mathrm{f}_{S o C}(S o C)\right] .
$$

The frequency curve may be expanded by an additional part to reduce the output frequency of the grid-forming BESS in order to trigger corresponding under-frequency relays that initiate load-shedding as mentioned above.

During island operation, the massively reduced short-circuit power leads to larger voltage excursions during imbalances of load and generation. In addition, during island operation, the power quality still remains an important issue.

\section{Simulation}

For the preparation of the field tests, a converter model in MATLAB/SIMULINK was created in order to investigate the expected behavior during island operation. The estimation of voltage dips during load-steps and start-up of motors was a goal to choose permissible sizes for the load and the motors. Furthermore, it was aimed to investigate the influence of control parameters on these 
voltage dips in order to get information under which conditions instabilities and maximum voltage dips during the field tests can be expected.

\subsection{Model Description}

The ability of a BESS to black-start and maintain a Microgrid relies on an appropriate control design of its converter, which has already been named grid-forming converter above. As many BESS not only operate in island mode but also in grid-connected mode, the control design of theirs converter has to be able to switch between these two operation modes. Based on a simplified converter model, Figure 2 shows an appropriate control design which is capable of operating in both "island mode" and "grid-connected mode".

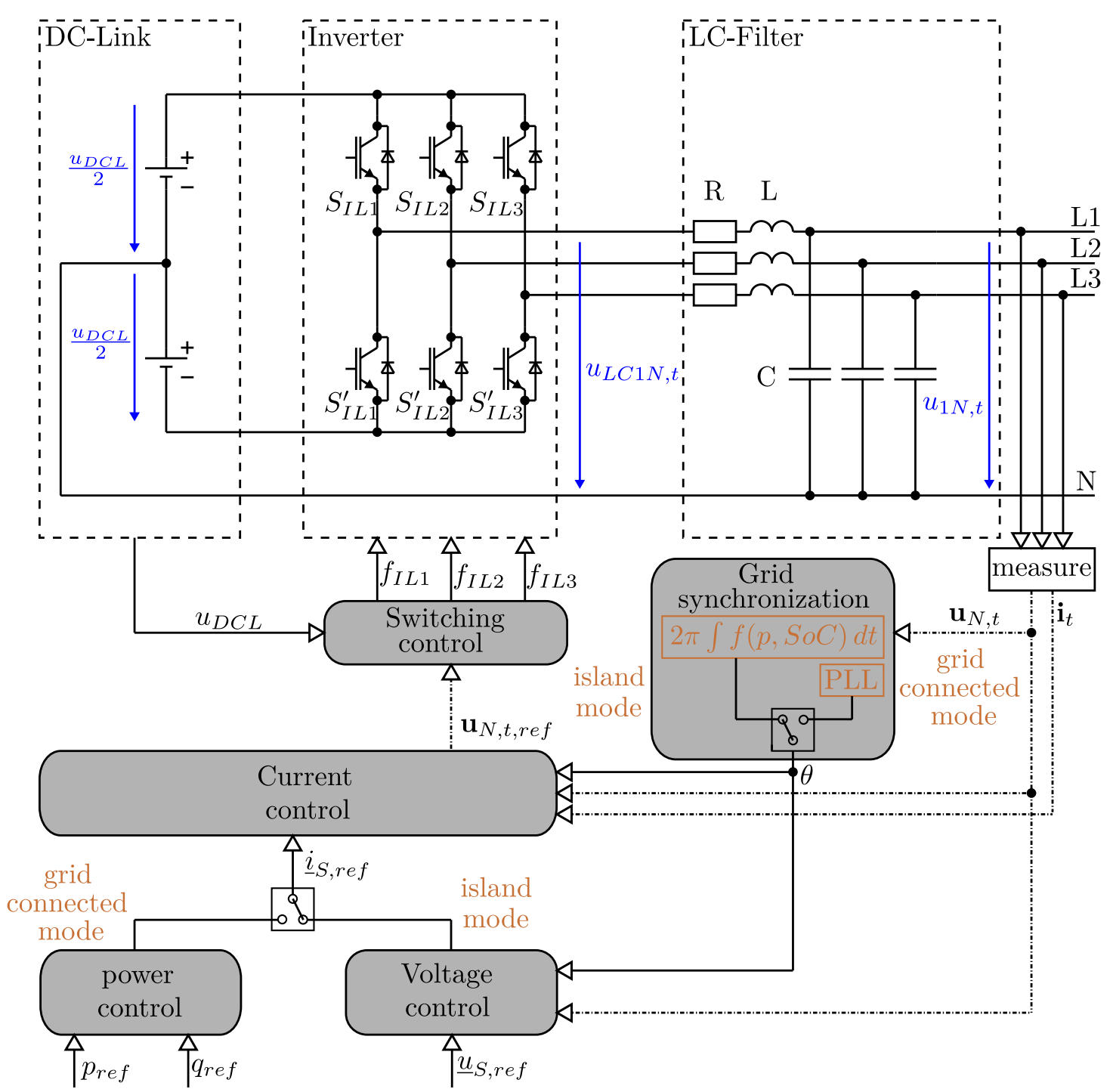

Figure 2. Converter model and its control to realize both island mode and grid-connected mode. The blue color indicates normalized voltages. The orange color indicates selectable control elements during grid-connected and island mode.

The simplified converter model of a three-phase voltage source converter (VSC) shown in Figure 2 is a two-level converter, which consists of a DC-Link, an inverter, and an LC-filter. For simplification, the DC-link is modeled as a constant voltage source. The inverter model consists of a self-commutated three-phase bridge, which is controlled by a pulse-width modulation signal. The resistance in the LC-filter at the output of the converter represents the parasitic resistance of the inductance. 
The lower part of Figure 2 shows the control structure of the converter model. It consists of a "grid synchronization", which builds the grid angle $\theta$. This grid angle is used in the "current control" to generate a reference voltage $\mathbf{u}_{N, t, r e f}$ based on a current reference space vector $\underline{i}_{s, r e f}$. The control structure includes two switches by which the operation mode, either grid-connected or island mode, and therefore a corresponding converter control structure is selected. In grid-connected mode, the current reference signal is generated by the "power control", which calculates $\underline{i}_{S, r e f}$ based on active- and reactive power reference signals $p_{r e f}$ and $q_{r e f}$. The grid angle $\theta$ during grid-connected mode is delivered via a synchronous reference frame phase-locked loop (SRF-PLL). During island mode, the grid angle $\theta$ is delivered based on a parametrizable value of the angular frequency $\omega$ with $\theta=\int \omega d t$. The current reference space vector during island mode is generated by the "voltage control", which uses a voltage reference space vector $\underline{u}_{S, r e f}$ to calculate it. The current control is followed by the "switching control" which generates the switching signals $f_{I L 1}, f_{I L 2}$ and $f_{I L 3}$ based on the voltage reference signal $\mathbf{u}_{N, t, r e f}$ and the DC-link voltage $u_{D C L}$ in order to control the switches $S_{I L 1}, S_{I L 2}$ and $S_{I L 3}$ of the inverter. The complementary switching signals $f_{I L 1}^{\prime}, f_{I L 2}^{\prime}$ and $f_{I L 3}^{\prime}$ are used to control the switches $S_{I L 1}^{\prime}, S_{I L 2}^{\prime}$ and $S_{I L 3}^{\prime}$ of the inverter. More details about the control structure during grid-connected mode can be found in $[21,22]$. For the simulations in this paper, only the control structure during island mode is relevant.

In island mode, the voltage- and current control builds a cascaded control structure, which is presented in more detail in Figure 3.

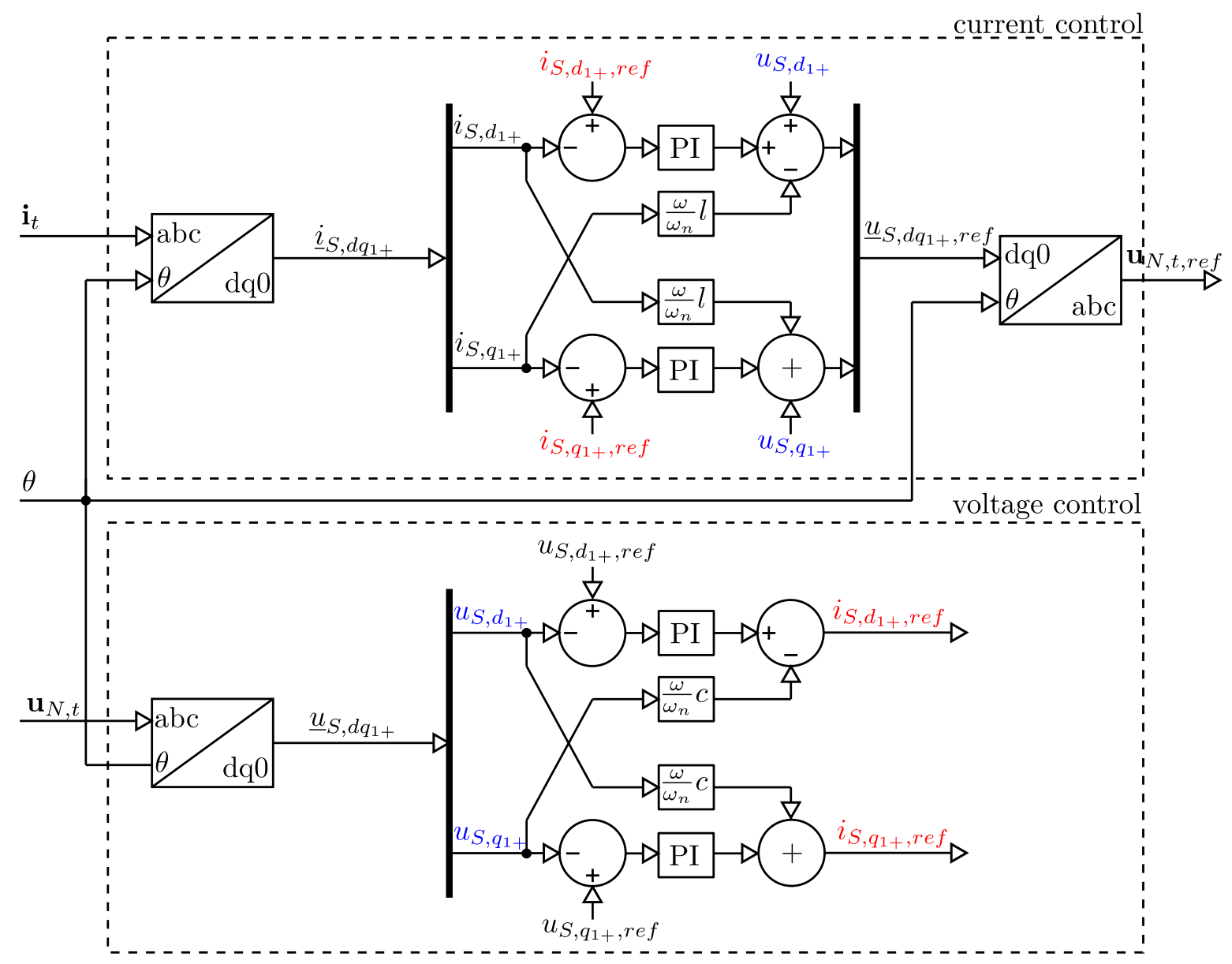

Figure 3. Cascaded voltage- and current control of Figure 2 in island mode.

Based on the grid angle $\theta$, the measured voltage- and current vectors $\mathbf{u}_{N, t}$ and $\mathbf{i}_{t}$ are used to calculate corresponding space vectors $\underline{u}_{S, d q_{1+}}$ and $\underline{\underline{i}}_{S, d q_{1+}}$ via Park-transformation. In the voltage control, the voltage space vector $\underline{u}_{S, d q_{1+}}$ is used to control the corresponding $\mathrm{d}$ - and q-components via PI-control based on a reference space vector $\underline{u}_{S, d q_{1+}, \text { ref }}$. The coupling between the $\mathrm{d}$ - and q-components due to 
the LC-filter is taken into account by corresponding decoupling terms $\frac{\omega}{\omega_{n}} c$, where $c$ is the normalized capacitance of the LC-filter, which is defined by $c=\frac{\omega_{n} C S_{n}}{U_{n}^{2}}$, with $S_{n}$ as the nominal apparent power and $U_{n}$ as the nominal voltage of the converter. The resulting current reference space vector $\underline{i}_{S, d q_{1+}, r e f}$ of the voltage control is used as input of the current control, which uses the current space vector $\underline{i}_{S, d q_{1+}}$ to control the corresponding $\mathrm{d}$ - and q-components via PI-control based on this current reference space vector. The coupling between the $\mathrm{d}$ - and q-components due to the LC-filter is taken into account by corresponding decoupling terms $\frac{\omega}{\omega_{n}} l$, where $l$ is the normalized inductance of the LC-filter, which is defined by $l=\frac{\omega_{n} L S_{n}}{U_{n}^{2}}$.

The tuning of the PI-controllers of the voltage- and current control can be conducted based on a stepwise approach according to Henninger [23], where the first step is the definition of a freely choosable time constant $\tau_{i}$ according to Yazdani and Iravani [24], which allows the current control to be represented by a first-order filter with the time constant $\tau_{i}$. The voltage control can then be tuned by using the symmetrical optimum according to Yazdani and Iravani [24]. The resulting parameters $K_{U, P}$ and $K_{U, I}$ of the PI-controllers of the voltage control and the parameters $K_{I, P}$ and $K_{I, I}$ of the PI-controllers of the current control based on this tuning approach result in the following definitions:

$$
\begin{gathered}
K_{I, P}=\frac{L}{\tau_{i}} \\
K_{I, I}=\frac{R}{\tau_{i}} \\
K_{U, P}=\frac{C}{\tau_{i}} \sqrt{\frac{1-\sin \Phi_{R}}{1+\sin \Phi_{R}}} \\
K_{U, I}=\frac{K_{U, P}}{\tau_{i}} \frac{1-\sin \Phi_{R}}{1+\sin \Phi_{R}}
\end{gathered}
$$

with $\Phi_{R}$ as the phase margin of the voltage control. A detailed description of the tuning of the PI-controllers of the voltage- and current control and a corresponding derivation of the parameters is given in [22]. Assuming the parameters of the LC-filter to be given, the tuning of the voltage- and current control is only dependent on the time constant $\tau_{i}$ and the phase margin $\Phi_{R}$.

Figure 4 shows the single line diagram of the Microgrid which is investigated in the simulation. This Microgrid is based on a real Microgrid which was also investigated in [25]. In an extended version of this Microgrid, field tests were also performed, which are presented in Section 3. It consists of a BESS based on Li-Ion technology with a rated power of 2.6 MVA, which is connected via line 1 to a $30 \mathrm{kV}$-substation. Via line 2 and a transformer, an active load and an asynchronous machine are connected to the substation.

As the Microgrid shown in Figure 4 consists of four battery converters, which are connected in parallel, the converter model shown in Figure 2 has to be adapted in order to consider this parallel connection. In case of a parallel connection of several converters, an equivalent converter model can be used by adapting the values of the LC-filter at the output of the model accordingly. Every single converter during a parallel operation behaves identically compared to a single operation. The only difference is the higher apparent power and the changed impedance due to parallel connection. 
Assuming the LC-filter of a single converter to be $L^{\prime}, R^{\prime}$ and $C^{\prime}$, the resulting values of the LC-filter of the equivalent converter model can be calculated by

$$
\begin{aligned}
& L=\frac{L^{\prime}}{n} \\
& R=\frac{R^{\prime}}{n}
\end{aligned}
$$

and

$$
C=n \cdot C^{\prime}
$$

with $n$ as the number of parallel connected converters. As the cascaded voltage- and current control shown in Figure 3 uses normalized values of the voltage $\mathbf{u}_{N, t}$ and the current $\mathbf{i}_{t}$ as input, the parameters of the PI-controllers for the equivalent converter model remain identical compared to the single converter model. The higher apparent power of the equivalent converter model

$$
S_{n}=n \cdot S_{n}^{\prime}
$$

only reflects in the normalization of the measured voltage $\mathbf{U}_{N, t}$ and current $\mathbf{I}_{t}$. Therefore, the control dynamics of the equivalent converter model is identical to the single converter model. Only the normalization and the LC-filter has to be adapted in the equivalent converter model compared to the single converter model.

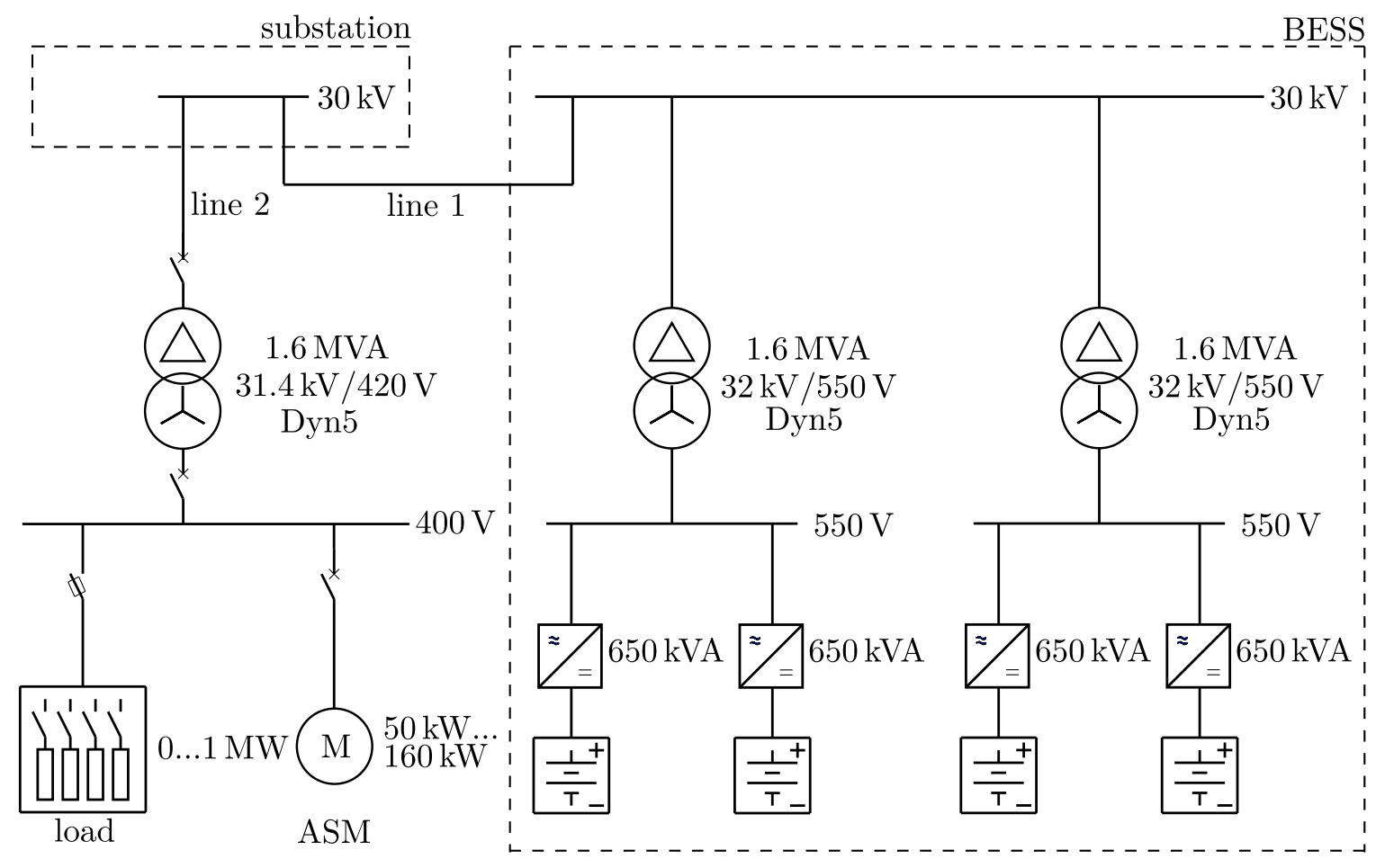

Figure 4. Single line diagram of the island grid investigated in the simulation.

The relevant parameters of the components of the Microgrid shown in Figure 4 are summarized in Table 1. 
Table 1. Parameters of the components in Figure 4 used in the simulation.

\begin{tabular}{ll}
\hline Characteristic & Value \\
\hline line 1 & \\
$R_{l 1}^{\prime}$ & $0.26 \Omega \mathrm{km}^{-1}$ \\
$L_{l 1}^{\prime}$ & $0.43 \mathrm{mH} \mathrm{km}^{-1}$ \\
length & $50 \mathrm{~m}$ \\
line 2 & \\
$R_{l 2}^{\prime}$ & $0.7 \Omega \mathrm{km}^{-1}$ \\
$L_{l 2}^{\prime}$ & $0.5 \mathrm{mH} \mathrm{km}-1$ \\
length & $40 \mathrm{~m}$ \\
transformers (values used for all transformers) & \\
$u_{k}$ & $0.06 \mathrm{pu}$ \\
$P_{K}$ & $13 \mathrm{~kW}, \mathrm{i} . \mathrm{e} ., 0.0082 \mathrm{pu}$ \\
equivalent converter model & \\
$n$ & 4 \\
$L$ & $L=\frac{L^{\prime}}{n}=\frac{260 \mu \mathrm{H}}{4}=65 \mu \mathrm{H}$ \\
$R$ & $R=\frac{R^{\prime}}{n}=\frac{1 \mathrm{~m} \Omega}{4}=0.25 \mathrm{~m} \Omega$ \\
$C$ & $C=n \cdot C^{\prime}=4 \cdot 342 \mu \mathrm{F}=1368 \mu \mathrm{F}$ \\
$\Phi_{R}$ & $50^{\circ}$ \\
\hline
\end{tabular}

\subsection{Simulation of Load-Steps and Motor Start-Ups}

As already mentioned in Section 1.3, an important property of a Microgrid is its robustness against load changes. Such load changes can be divided into active- and reactive load changes. In the simulations as well as in the field tests, the significant active- and reactive load changes of a residential grid section are reproduced by a load-bank and motor start-ups. During the island operation of a Microgrid, its robustness against such load changes may be crucial to guarantee a stable grid operation with sufficient power quality. According to Bagert et al. [26], a value of 0.8 pu can be assumed as reasonable value for a minimum dynamic voltage drop in a Microgrid. The converter model described in Section 2.1, therefore, is used to simulate the voltage drop during load-steps and the start-up of motors in order to identify the minimum dynamic voltage drop that can be expected during the field tests. Based on these simulations, the choice of the size of the loads and the motors for the field tests is made. As these voltage drops are depending on the control parameters of the converter, their influence is investigated in order to provide corresponding information for the field tests. This also applies to the motors, the successful start-up of which also depends on the control parameters.

The load bank shown in Figure 4 represents a impedance load, which is used to simulate active power load-steps. Figure 5 shows the results of the simulation of an active power load-step of $800 \mathrm{~kW}$ through the load bank.

Figure $5 a$ shows the active power, Figure $5 b$ the reactive power, Figure $5 c$ the voltage at the PCC of the BESS, and Figure $5 \mathrm{~d}$ the voltage at the connection point of the asynchronous machine. The different curves show the results for different values of the converter control time constant $\tau_{i}$, which defines the parameters for the PI-controllers of the voltage- and current control shown in Figure 3 according to Equations (2)-(5). Other than in the main grid, where an active power load-step usually is coupled with a change in the frequency, the frequency in the islanded Microgrid is fixed at a value of $f=\frac{\omega_{n}}{2 \pi}$ in case no frequency droop characteristic is included in the control structure shwon in Figure 2. An active power load-step in the islanded Microgrid, therefore, only leads to a voltage drop, which is to be controlled by the converter control. With an increasing value of $\tau_{i}$, the voltage drop at the converter terminals increases as well. A higher time constant $\tau_{i}$ results in a longer settling process until the stable active power operating point of $800 \mathrm{~kW} \equiv 0.3 \mathrm{pu}$ is reached. With a time constant of $\tau_{i}=0.4 \mathrm{~ms}$, the voltage drop at the converter terminals leads to a value of $u=0.4 \mathrm{pu}$. Due to the influence of the transformers and lines in the Microgrid, the voltage drop at the $400 \mathrm{~V}$-bus of the load bank has slower dynamics and leads to a less drastic voltage drop to a value of $u=0.8 \mathrm{pu}$. 


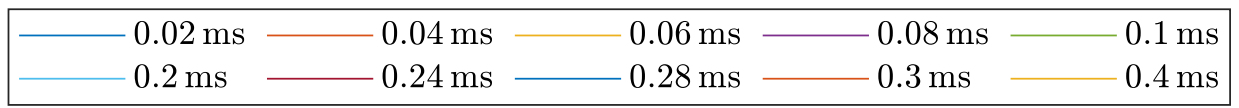

(a) active power
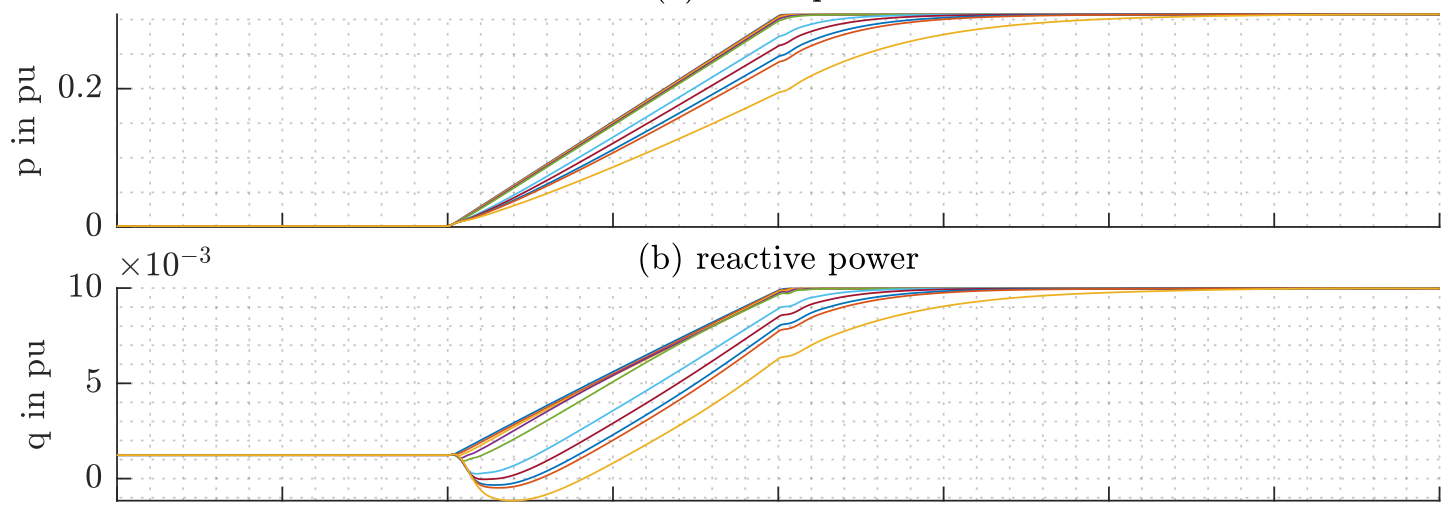

(c) voltage at converter terminals

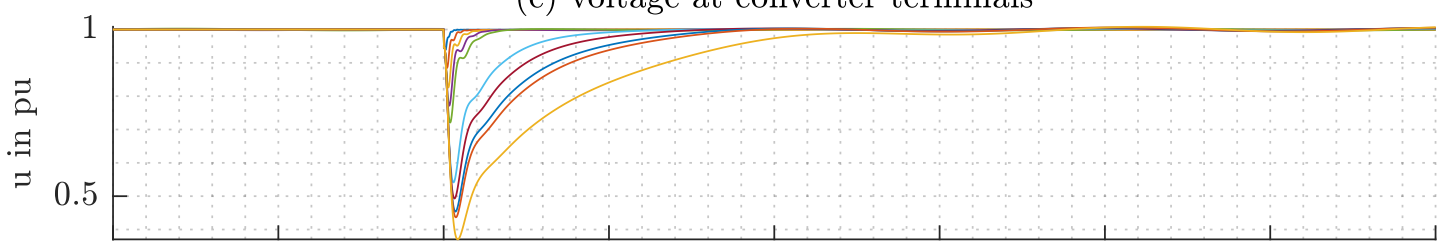

(d) voltage at load

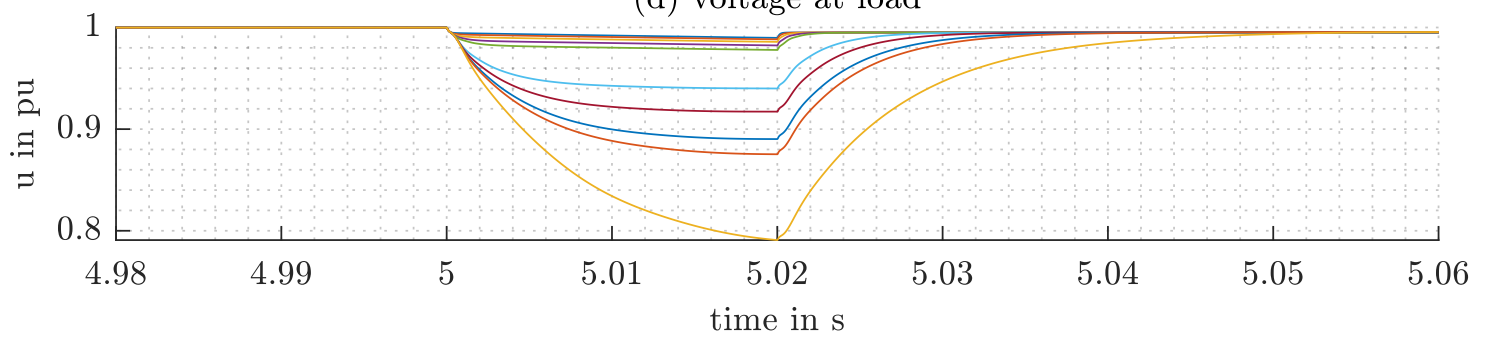

Figure 5. Results of the simulation of a load-step of $800 \mathrm{~kW}$ for different values of $\tau_{i}$.

Figure 6 shows a sensitivity analysis of the minimum voltages, at the PCC of the converter, and the $400 \mathrm{~V}$-bus of the load bank, over the settling time, until a stable operating point of the active power is reached. For this consideration, the settling time is defined as the duration between the beginning of a load-step and the moment when the voltage gradient during the voltage restoration process becomes smaller than $0.3 \mathrm{pu} / \mathrm{s}$. The minimum voltages $\min \left(u_{C}\right) \approx 0.4 \mathrm{pu}$ and $\min \left(u_{\text {load }}\right) \approx 0.8 \mathrm{pu}$ of Figure 5 with a time constant of $\tau_{i}=0.4 \mathrm{~ms}$ are marked in Figure 6. Especially for low values of the time constant $\tau_{i}$, the size of the voltage drop and the corresponding duration of the settling process back to a nominal value is very sensitive to changes of $\tau_{i}$. Regarding power quality, the voltage at the load is relevant. The corresponding voltage behavior can be classified as a short voltage dip, which is not likely to affect the operation of connected devices in the Microgrid.

Based on the assumption that a voltage drop to $0.8 \mathrm{pu}$ is considered as the minimum dynamic voltage drop according to Bagert et al. [26], a maximum load-step of $800 \mathrm{~kW}$ is selected to be used in the field test, taking into account that the control parameters of the real converter are parametrized faster than a corresponding $\tau_{i}=0.4 \mathrm{~ms}$.

Besides the influence of an active power load-step, the influence of a reactive power load-step is also relevant during island operation. When starting an asynchronous machine, its starting current reaches values five to seven times higher than its nominal current. A motor start-up, therefore, can be used to simulate a massive reactive load-step in the Microgrid. Figure 7 shows the results of the simulation of a start-up of a $160 \mathrm{~kW}$ asynchronous machine to investigate such a situation of a massive reactive power load-step. 


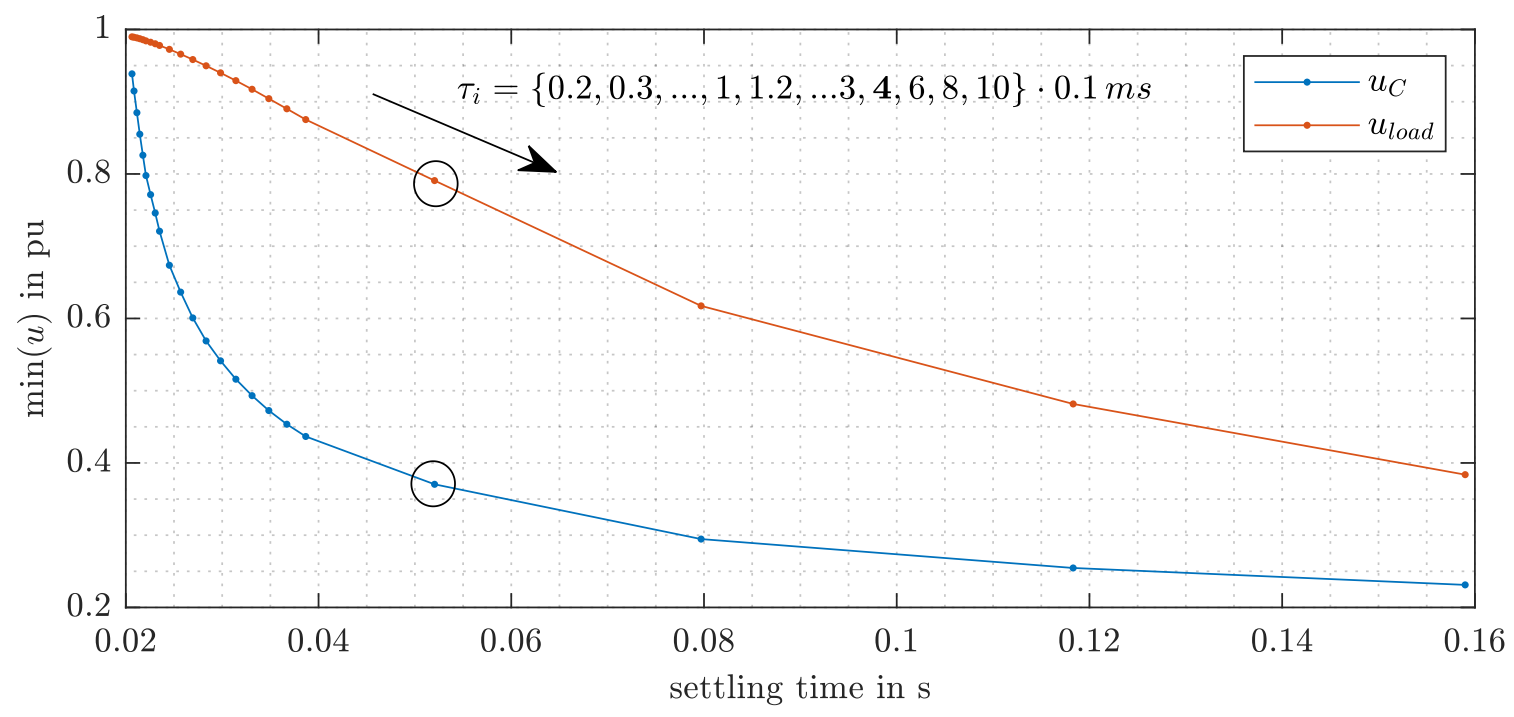

Figure 6. Sensitivity analysis of the influence of a $800 \mathrm{~kW}$ load-step on the voltage $u_{C}$ at the PCC of the converter and the voltage $u_{\text {load }}$ at the connection point of the load in dependence of the settling time until a stable operating point of the active power is reached. The results of $\tau_{i}=0.4 \mathrm{~ms}$ are circled.

$-0.02 \mathrm{~ms}-0.04 \mathrm{~ms}-0.06 \mathrm{~ms}-0.08 \mathrm{~ms}-0.09 \mathrm{~ms}-0.1 \mathrm{~ms}$

(a) active power

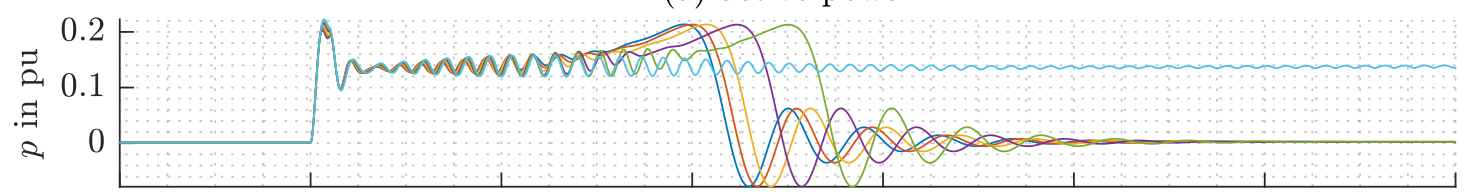

(b) reactive power

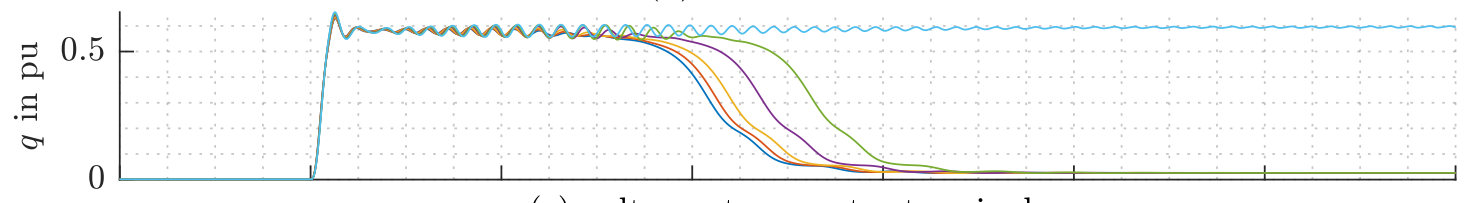

(c) voltage at converter terminals
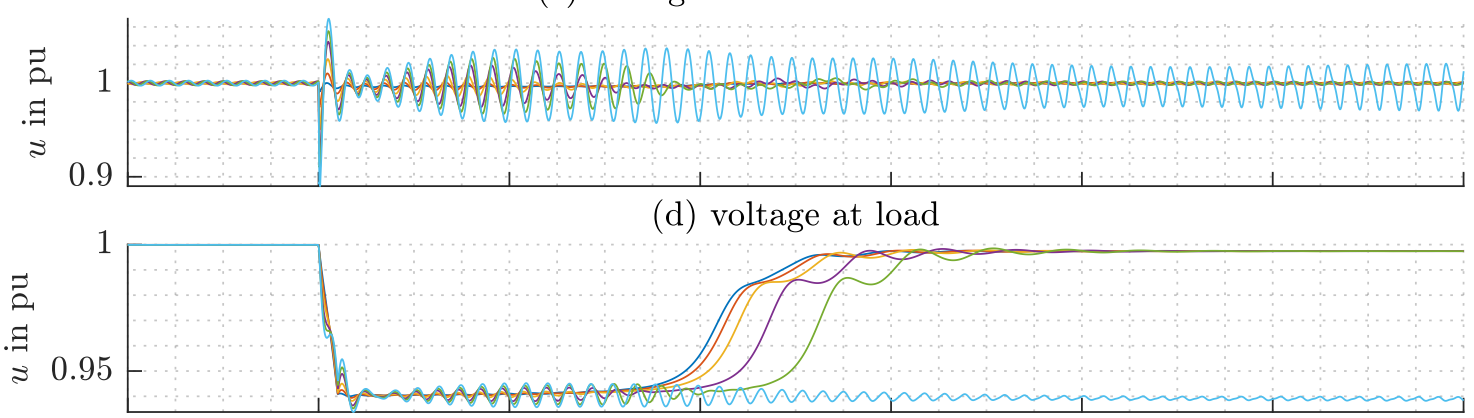

(e) speed

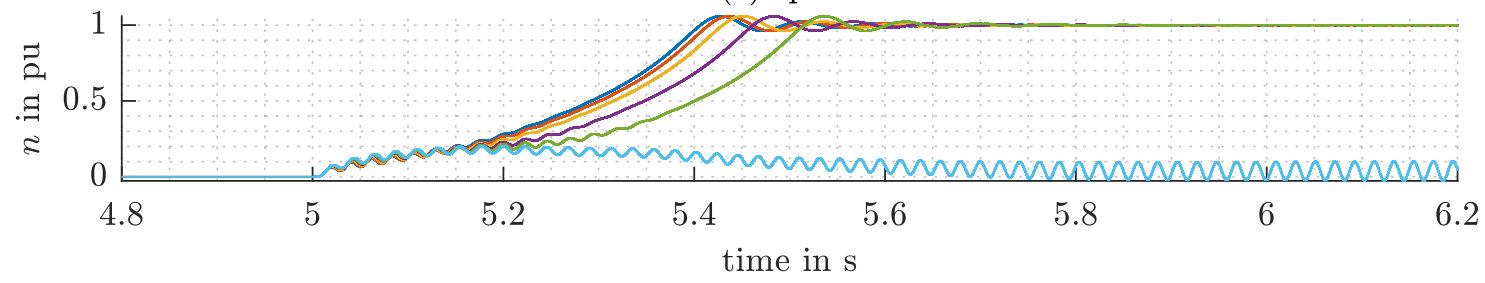

Figure 7. Results of the simulation of a motor start-up of a $160 \mathrm{~kW}$ asynchronous machine for different values of $\tau_{i}$. 
The parameters of the asynchronous machine are defined by a preset-model available in MATLAB/SIMULINK. Figure 7a shows the active power, Figure $7 \mathrm{~b}$ the reactive power, Figure $7 \mathrm{c}$ the voltage at the PCC of the BESS, Figure 7d the voltage at the $400 \mathrm{~V}$-bus of the asynchronous machine, and Figure 7e shows the speed of the asynchronous machine. The different curves show the results for different values of the converter control time constant $\tau_{i}$. With the increasing value of $\tau_{i}$, the voltage at the PCC of the converter starts to oscillate, resulting in oscillations of the active- and reactive power. With values higher than $\tau_{i}=0.09 \mathrm{~ms}$, the asynchronous machine can no longer be started. The corresponding results for an unstable motor start-up with $\tau_{i}=0.1 \mathrm{~ms}$ are also shown in Figure 7 . Figure 7e shows that the motor is not able to reach nominal speed any more. Therefore, the active- and reactive power demands remain at rather high values. This results in an ongoing voltage drop at the $400 \mathrm{~V}$-bus of the motor. A converter controller time constant of $\tau_{i}=0.1 \mathrm{~ms}$ poses the stability limit for the start-up of a asynchronous machine with an apparent power of $160 \mathrm{~kW}$ in the Microgrid. Only with lower values of $\tau_{i}<0.1 \mathrm{~ms}$ is a motor start-up possible. Such stability limits can be determined for different motor sizes. Table 2 summarizes these stability limits.

Table 2. Summary of stability limits for different motor types.

\begin{tabular}{ll}
\hline Preset Model Motor Type & Largest Value of $\tau_{i}$ \\
\hline $37 \mathrm{~kW}$ & $0.4 \mathrm{~ms}$ \\
$75 \mathrm{~kW}$ & $0.2 \mathrm{~ms}$ \\
$110 \mathrm{~kW}$ & $0.1 \mathrm{~ms}$ \\
$160 \mathrm{~kW}$ & $0.09 \mathrm{~ms}$ \\
\hline
\end{tabular}

Table 2 lists the largest time constant $\tau_{i}$ with which a start-up of the corresponding motor is still possible. The different motor types represent the available preset-models in MATLAB/SIMULINK. Only a motor size of $200 \mathrm{~kW}$ was available for the field tests. However, based on the results of Table 2, with a parameterization of control parameters on the real converter which are faster than a corresponding $\tau_{i}=0.09 \mathrm{~ms}$, it can be assumed that a successful start-up during the field tests is possible.

\section{Field Tests}

During the field tests, a small residential grid section was disconnected from the main grid in order to build an islanded Microgrid. More details about the field test setup can also be found in [25,27]. The corresponding single line diagram of this Microgrid is shown in Figure 8 and consists of the BESS, which has already been described in Section 2.1, a local grid, which acts as "artificial" representation of a low voltage grid, and a wind park feeder.

The local grid consists of a freely adjustable active power load bank and an asynchronous machine, which acts as reactive power sink. This local grid is capable of imitating massive load changes of a low voltage grid. The wind park consists of several feeders, each of them serially connecting several wind turbines. Each of these wind turbines has an apparent power of $3 \mathrm{MVA}$, which is fully deployed at a wind speed of $13 \mathrm{~m} \mathrm{~s}^{-1}$.

One of these feeders, which serially connects two wind turbines, is connected to the islanded Microgrid, the other feeders were disconnected during the field test. The single line diagram shown in Figure 4 which was used for simulation is identical to the single line diagram shown in Figure 8, but does not include the wind park as it was not considered in the simulation model in Section 2.1. The goals of the field test include the investigation of

- the black-start of the Microgrid,

- the synchronization of the wind park to the Microgrid,

- the island operation with an active power infeed of the wind park, where an implementation of the frequency control characteristic described in Section 1.3 based on a master-slave control approach is active and

- the investigation of active- and reactive load changes of the local grid. 
The findings of the corresponding field tests are described in the following sections.

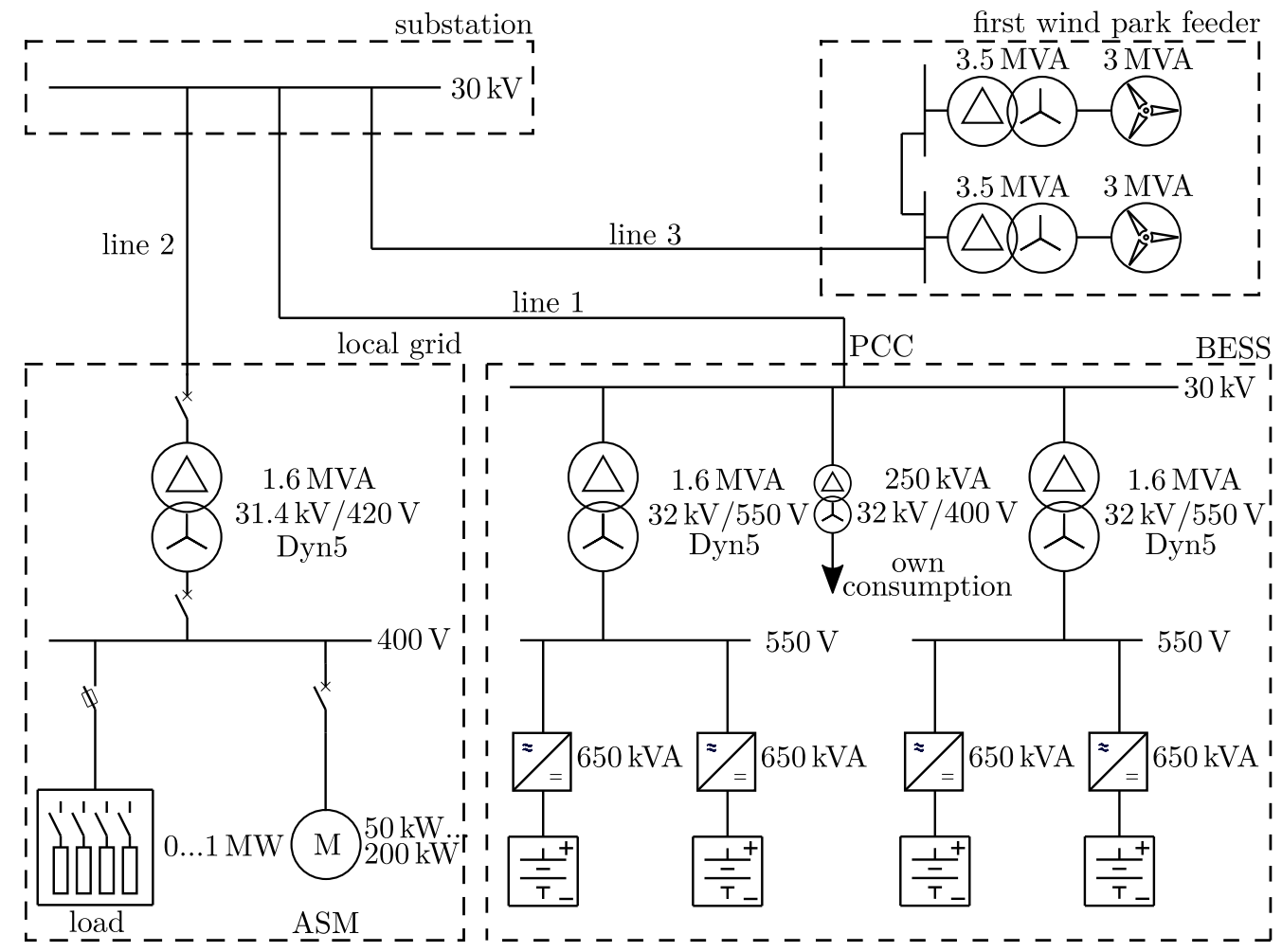

Figure 8. Single line diagram of the island grid investigated in the field tests.

\subsection{Black-Start of the Microgrid}

As already mentioned, the cold load pickup during the black-start of a Microgrid is a challenging issue. The corresponding high current demand of the cold load pickup may be misinterpreted as fault condition by the protective relays and therefore carries the risk of preventing a successful black-start as the protective relays may trip. An example for the behavior of the cold load pickup is shown in Figure 9, which presents the current demand during connection of the auxiliary transformer of the Microgrid shown in Figure 8.

Due to the nonlinear relationship of the flux and the magnetizing current of the transformer, the connection of the transformer leads to high current peaks during the first several cycles. Their magnitude is initially $6-10$ times higher than the rated load current. The auxiliary transformer with a nominal power of $250 \mathrm{kVA}$ has a rated load current of $4.6 \mathrm{~A}$, which corresponds to a current demand of $0.1 \mathrm{pu}$ for the BESS. The maximum expected inrush current corresponds to a current demand of $1 \mathrm{pu}$ for the BESS. The magnitude of the inrush current shown in Figure $9 \mathrm{~b}$ is about $0.35 \mathrm{pu}$ and, therefore, only 3.5 times higher than the rated current. The magnitude depends on the exact time of connection and the corresponding angle of the phase voltage. The maximum inrush current results from a time of connection when the magnitude of the phase voltage is in its minimum. Figure 9a shows that the phase voltages $u_{2 N, t}$ and $u_{3 N, t}$ have a magnitude of about $50 \%$ and, therefore, the resulting inrush current is lower than the maximum expected one.

Building on the findings of Figure 9, it can be stated that a black-start of the Microgrid shown in Figure 8, with connected transformers of the wind park and the local grid, would lead to a current demand much higher than the current capabilities of the BESS. However, it is possible to gradually increase the output voltage of the BESS while all transformers are connected to the Microgrid. By doing so, inrush currents, which result from switching actions that connect feeders with corresponding transformers, can be prevented. A measurement of such a gradual increase of the supplying voltage is shown in Figure 10. 
(a) voltages

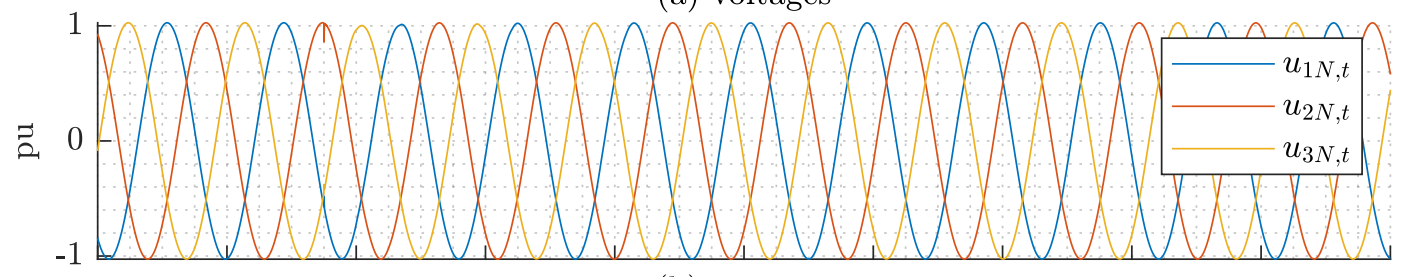

(b) currents

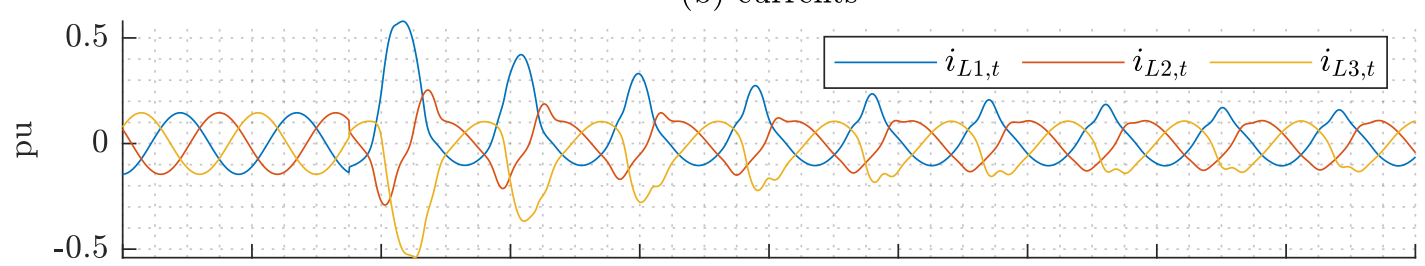

(c) instantaneous powers

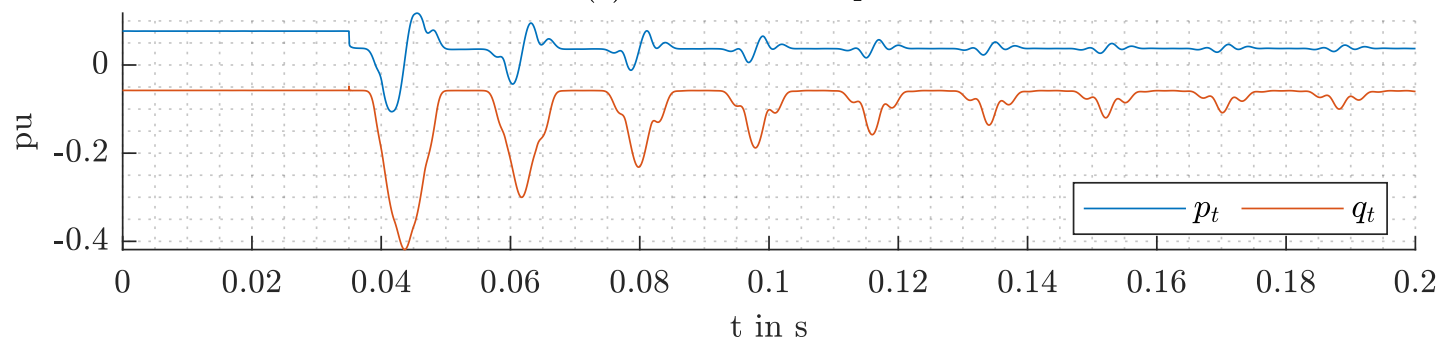

Figure 9. Measurement of the inrush current of the own auxiliary transformer of the Microgrid shown in Figure 8.

(a) voltages

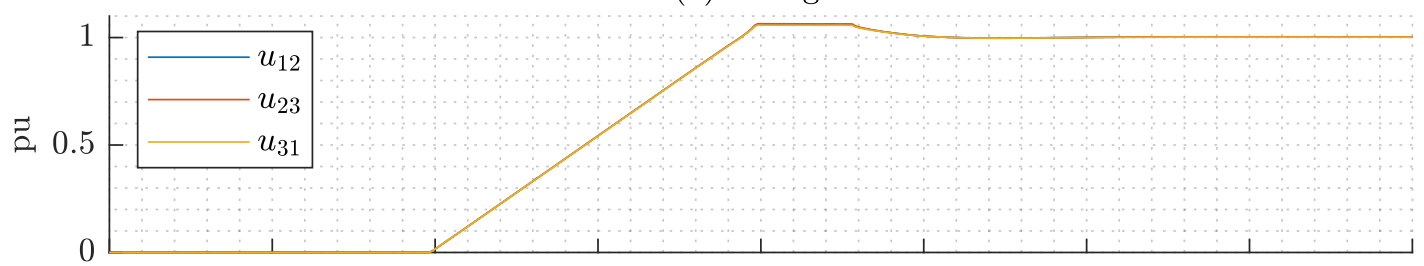

(b) total harmonic distortion (voltage)

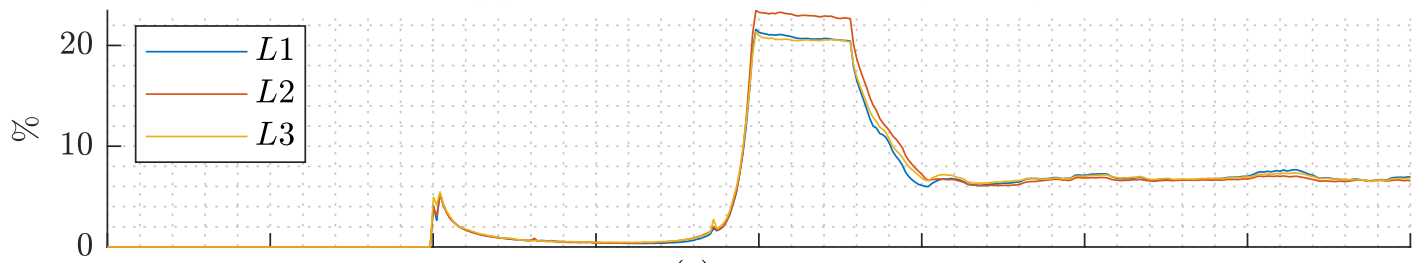

(c) currents

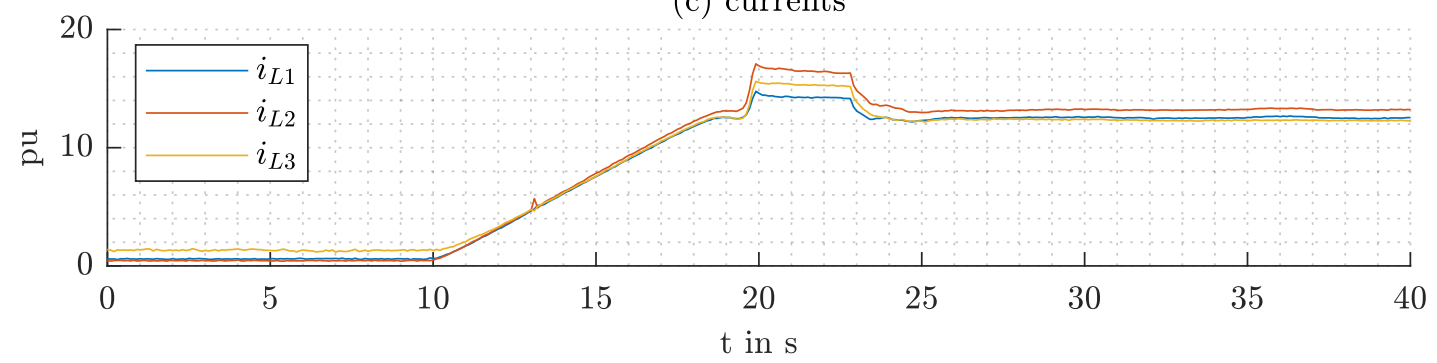

Figure 10. Measurement of voltages and current during a gradual increase of the voltage of the BESS in the Microgrid shown in Figure 8 while all transformers are connected. The small peak in $i_{L 2}$ can be considered as measurement error. Between $20 \mathrm{~s}-25 \mathrm{~s}$, the voltage exceeds a value of 1 pu due to a high level of harmonics, indicated by the total harmonic distortion in (b), which leads to higher root-mean-square values of the voltages. 
Figure 10 shows a gradual increase of the output voltage of the BESS within $10 \mathrm{~s}$. Figure 10b shows that the current demand during this black-start of the Microgrid is only about $5 \%$ of the current capability of the BESS. About $15 \mathrm{~s}$ after the black-start, a stable supply voltage of $1 \mathrm{pu}$ is reached and all feeders of the Microgrid are supplied.

\subsection{Synchronization of the Wind Park to the Microgrid}

After a black-start of the island grid, the wind turbines are able to synchronize with the supply voltage in the Microgrid. A wind turbine follows a start-up routine when it is activated from a state where it is switched off. The first step in this routine is the supply of its auxiliary systems, which, for example, includes the motors of the pitch control of the rotor blades (pitch drive) and the motor which aligns the wind turbine in the wind direction (azimuth drive). In the second step, the mechanical brake of the rotor of the wind turbine is released. In this "idle mode", the rotor rotates dependent on the wind speed, but no power infeed takes place. The measurement of a constant wind speed or a corresponding angular frequency of the rotor over a time period of several minutes, which lies above a minimum threshold, heralds the third step of the start-up routine. In the third step, the actual synchronization takes place, where the converter of the wind turbine synchronizes with the supply voltage in the Microgrid and starts to feed in active power, dependent on the actual wind speed and the corresponding angular frequency of the rotor.

\subsection{Island Operation with an Active Frequency Control Characteristic}

The frequency control characteristic shown in Figure 1 has been described as a simple possibility to integrate DER in the Microgrid based on a master-slave control approach. Such a frequency control characteristic was implemented in the BESS of the Microgrid by simply altering the value $\omega=2 \pi f(p, S o C)$ of the grid synchronization shown in Figure 2 according to the curve in Figure 1, which leads to a grid angle $\theta=2 \pi \int f(p, S o C) d t$. The behavior of such a control approach was measured during island operation after successfully synchronizing the wind park. The wind turbines in Microgrid support LFSMO with corresponding options for its parameterization. This parameterization was carried out according to the frequency curve shown in Figure 1 via several parameterizable fulcrums. The reaction of an activated LFSMO on the wind turbines works as a percentual power reduction in relation to the reference operating point of the wind turbine. For example, assuming a wind speed of $10 \mathrm{~m} \mathrm{~s}^{-1}$ leads to a reference operating point of the wind turbine of $50 \%$ of its nominal power, this reference operating point is executed directly as actual power output at $50 \mathrm{~Hz}$ and this reference operating point is executed as reduced power output point according to the frequency characteristic shown in Figure 1 at higher frequencies.

A measurement result of an islanded Microgrid operation, during which the frequency control approach mentioned above is active and the wind turbines are synchronized and feeding in power, is shown in Figure 11.

The field test started with a SoC of the BESS of $50 \%$ and an active power infeed of the wind park. Figure $11 \mathrm{~b}$ shows the stepwise increase of the SoC of the BESS, which has been achieved by a manual narrowing of the usable SoC-window of the BESS. This manual change of the SoC was applied in order to shorten the time period of the field test. Due to the stepwise change of the SoC, the frequency needs some time to reach the corresponding reference value of the frequency control characteristic. The vertical lines represent these time periods. During these gradual changes of the frequency, the wind turbines reduce their currently possible power output $P_{D E R}^{\prime}$ to a reduced power output $P_{D E R}$ according to the corresponding reference curve, which is shown in Figure 11a. During the time period of this gradual change of the frequency, the wind speed can be considered constant. In contrast, the time between manual changes of the usable SoC-window is quite long. Therefore, during these manual changes of the usable SoC-window, the wind speed and the corresponding power infeed of the wind park change. The horizontal lines of the power infeed in Figure 11a are related to these changes of the 
wind speed and the corresponding operating point $P_{D E R}^{\prime}$ of the wind park. Nevertheless, Figure 11 proves to be a successful application of the frequency control approach according to Figure 1.
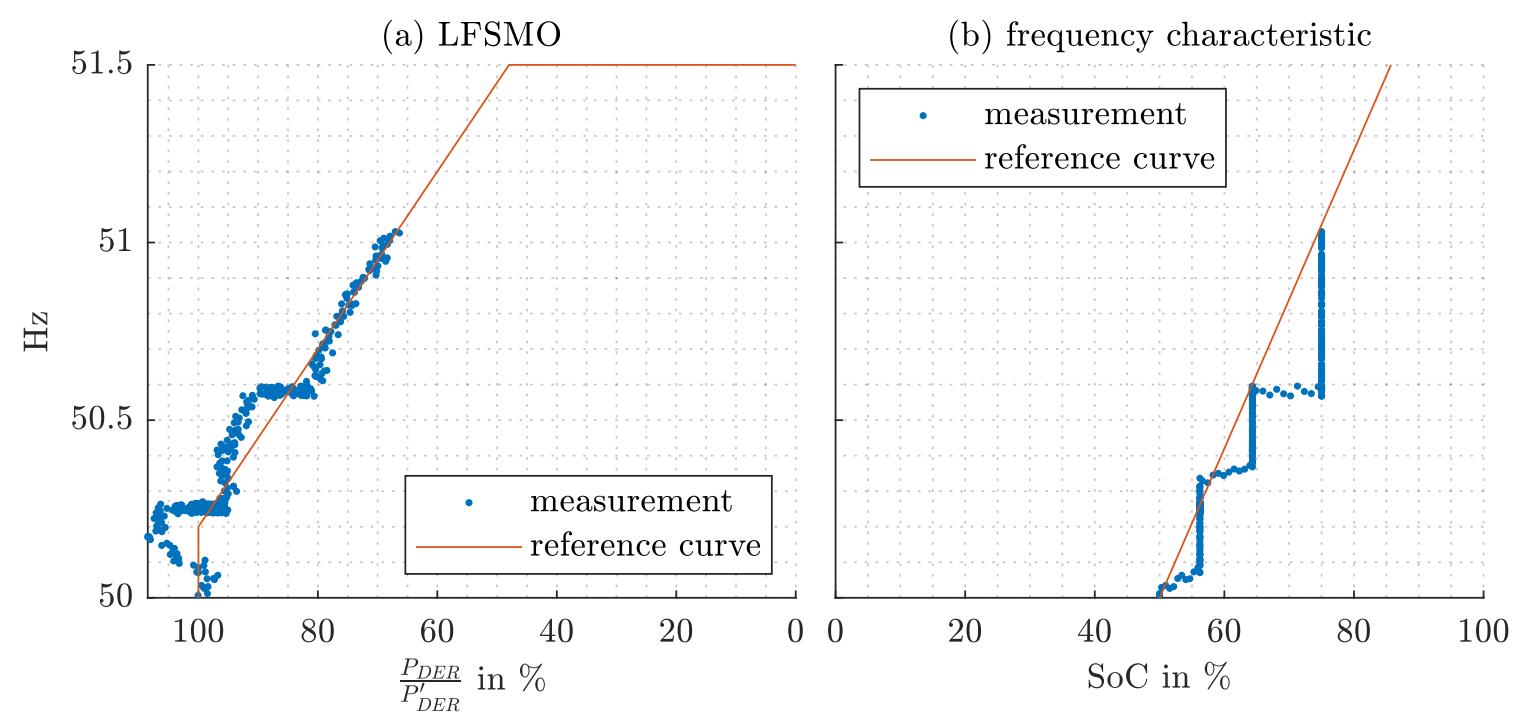

Figure 11. Measurement of the frequency control characteristic according to Figure 1.

\subsection{Load Changes during Island Operation}

The local grid of the Microgrid shown in Figure 8 is used to imitate significant load increases of a residential low voltage grid. The active power load bank consists of several resistors, which are connected to each other depending on which active power consumption is to be achieved. Figure 12 shows the measurement results of two load-steps of $200 \mathrm{~kW}$ and $800 \mathrm{~kW}$ and their influence on the voltage at the PCC of the BESS. During these load changes, the wind turbines were deactivated. Since the frequency characteristic in Figure 1 only influences the frequency when $p>0 \wedge p>p_{0}$ or when $S o C>0 \wedge S o C>S o C_{0}$ and a load-step leads to $p<0$, the frequency during the load changes can therefore be considered to be constant $f=50 \mathrm{~Hz}$ when assuming a state of charge of about $\mathrm{SoC}=50 \%$.

The load-steps are coupled with a highly dynamic voltage drop, similar to the simulation results shown in Figure 5. However, the stabilization of the voltage to the nominal value takes about $4 \mathrm{~s}$ for both load-steps, which is much longer than observed in the simulations. Compared to the model used in the simulations, the control algorithms in the real converter are more complex and additional output filters are installed, which both explain the differences between field test and simulation. The voltage in Figure 5 does not fall below the value of of $0.8 \mathrm{pu}$, which is considered as the minimum dynamic voltage drop according to Bagert et al. [26].

The asynchronous machine of the local grid shown in Figure 8 is used to imitate massive reactive load changes of a typical low voltage grid. Figure 13 shows the measurement results of the start-up of two asynchronous machines with a nominal power of $50 \mathrm{~kW}$ and $200 \mathrm{~kW}$ and their influence on the voltage at the PCC of the BESS. The measurement results show a similar behavior compared to the simulation results shown in Figure 7.

As already described for the active power load changes the differences between the measurementand simulations results can be explained by the much more complex control structure of the real converter. 

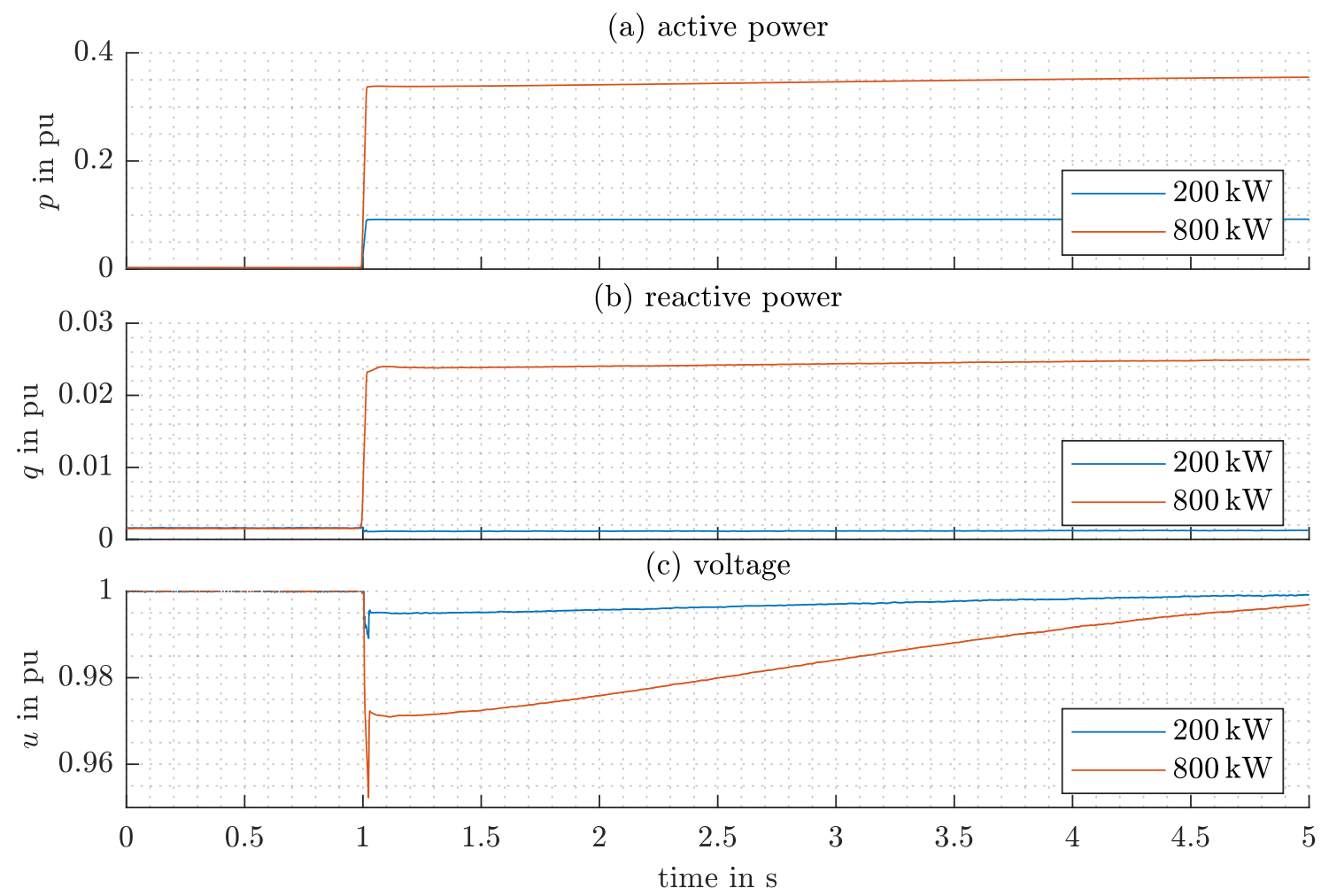

Figure 12. Measurements during an active power load-step of $200 \mathrm{~kW}$ and $800 \mathrm{~kW}$. The voltage $u$ is the mean value of all normalized line-to-line voltages.

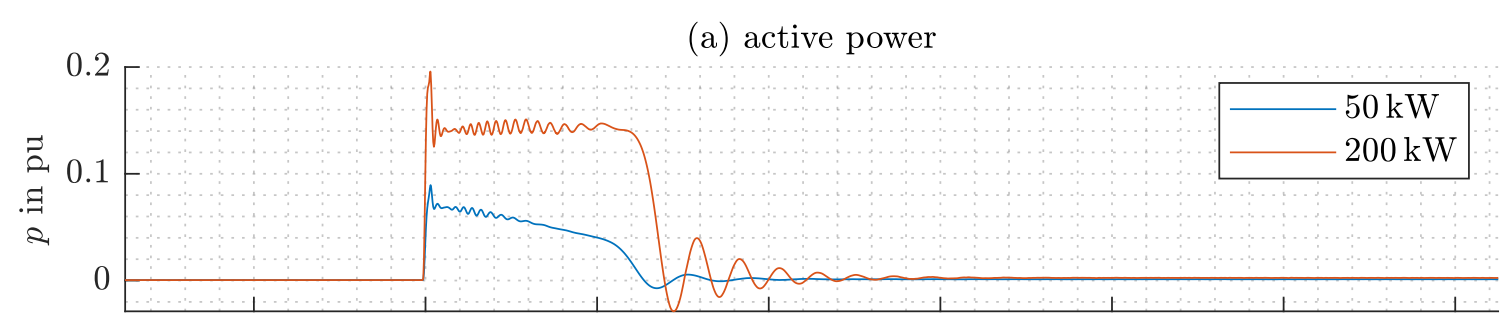

(b) reactive power

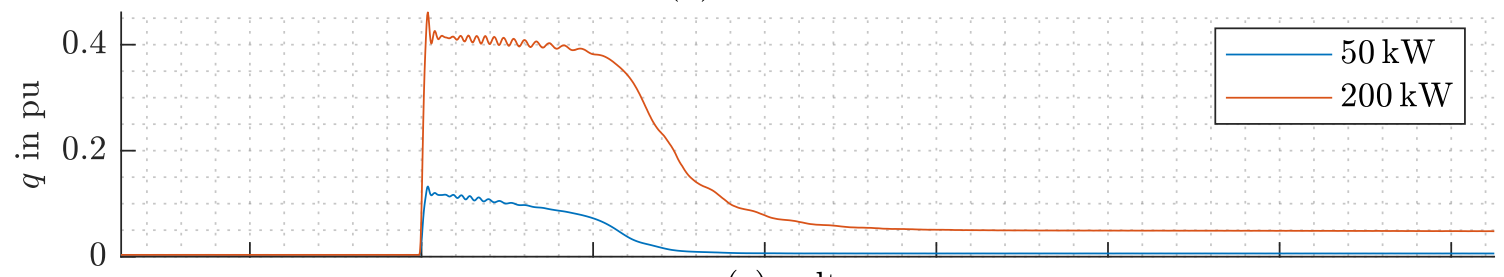

(c) voltage

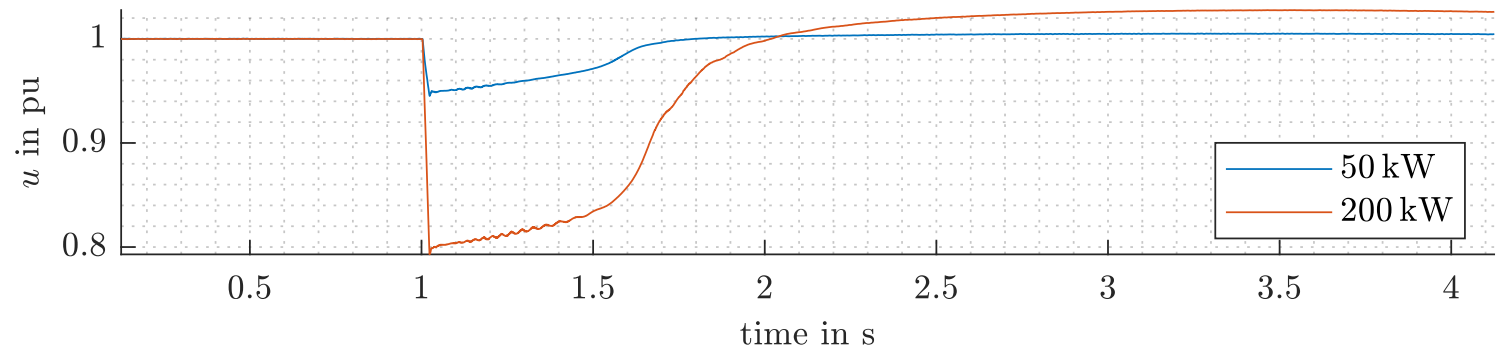

Figure 13. Measurements during the motor start-up with a nominal power of $50 \mathrm{~kW}$ and $200 \mathrm{~kW}$. 


\subsection{Power Quality}

Besides the voltage drops during load changes, which affect the power quality in a Microgrid, the occurrence of harmonics is another issue that affects the power quality. As shown in Figure 10, a high value of the total harmonic distortion (THD) may occur during the black-start of a Microgrid, which reaches a value of up to $20 \%$ in Figure 10b. Table 3 summarizes the THD for different operating points and situations during the field tests.

Table 3. Measured THD for different operating points and situations during the field tests.

\begin{tabular}{llll}
\hline Operating Point & Value of THD & Situation & Value of THD \\
\hline$p=0.08 \mathrm{pu}$ & $2.5 \%$ & running $50 \mathrm{~kW}$-motor & $0.6 \%$ \\
$p=0.16 \mathrm{pu}$ & $2 \%$ & running $200 \mathrm{~kW}$-motor & $0.4 \%$ \\
$p=0.24 \mathrm{pu}$ & $1.5 \%$ & synchronization of wind turbines & $15 \%$ \\
$p=0.32 \mathrm{pu}$ & $1 \%$ & $p=-0.2 \mathrm{pu}$ (moderate power infeed of wind turbines) & $5 \%$ \\
\hline
\end{tabular}

The measurement results in Table 3 show a decreasing trend of the THD for an increasing value of the active power operating point $p$ of the BESS. This can be explained by the fact that the associated converter of the BESS has been optimized for operation at $p=0.8 \mathrm{pu}$. Besides the rather high THD of $20 \%$ during the black-start of the Microgrid, as shown in Figure 10, during the synchronization of wind turbines, a similar high THD of $15 \%$ occurs. During the power infeed of wind turbines, the THD reaches a moderate level of $5 \%$.

\subsection{Discussion}

In summary, the field tests prove that the BESS shown in Figure 8 is capable of performing a black-start of the Microgrid by using a gradual increase of the supply voltage during start-up. During island operation, the application of a frequency control characteristic based on a master-slave control approach allows the integration of DER with nominal powers higher than the BESS into the Microgrid, while also carrying out an appropriate energy management by guaranteeing the $\mathrm{SoC}$ of the BESS within allowable limits. The BESS is capable of controlling active- and reactive load changes, which are considered to be representative for significant load changes in a residential grid section, with an acceptable level of power quality, indicated by voltage drops not to fall below a value of $0.8 \mathrm{pu}$ and by the THD, which only reaches high values during the black-start of the Microgrid and the synchronization of wind turbines.

\section{Conclusions}

In this paper, the black-starting and islanding capabilities of a BESS, which acts as grid-forming unit in a Microgrid, consisting of a wind park, a load and asynchronous machines, were investigated. The methodology for investigation is based on simulation in MATLAB/SIMULINK and the conduction of field tests. For the simulation, a simplified converter model is used, which allows the simulation of active- and reactive load changes during island operation. The simulation provides the basis for the selection of loads and motors for the field test and allows an estimation of the behavior during the field tests. Based on a master-slave control approach, a frequency characteristic is presented, which allows a proper power reduction of slave-units, without the further need for communication. The BESS represents the master-unit that controls the frequency, while DER represent slave-units, which vary their power output depending on the frequency. By applying this control approach, the operation and power infeed of DER with nominal powers higher than the BESS is possible, while also allowing an appropriate energy management to control the SoC of the BESS. An application of such an approach in Microgrids, which are "embedded" into the interconnected power grid, in order to ensure a backup supply during blackouts, therefore is possible very easily, as no further communication is necessary. By providing such an application of backup supply, a "value stacking" of BESS is possible and can increase the profitability of such a system when the service of backup supply is provided in addition to 
other services such as frequency control. In the field tests, the capabilities of the BESS to handle activeand reactive load changes were investigated. Furthermore, the master-slave control approach was implemented in the BESS and investigated during the field tests. After the successful black-start of the Microgrid, it could also be demonstrated that the BESS is capable of handling active- and reactive load changes and the master-slave control approach is applicable and works in a real Microgrid.

A future research goal is the investigation of protection schemes and their application in Microgrids supplying real low-voltage feeders instead of artificial ones.

Author Contributions: Conceptualization, J.M. and W.G.; Formal analysis, J.M.; Funding acquisition, W.G.; Methodology, J.M.; Software, J.M.; Supervision, W.G.; Visualization, J.M.; Writing-original draft, J.M.; Writing-review and editing, W.G. All authors have read and agreed to the published version of the manuscript.

Funding: This work received no external funding.

Acknowledgments: The publication of this article was supported by the Open Access Funding by TU Wien University Library.

Conflicts of Interest: The authors declare no conflict of interest.

\section{Appendix A. List of Symbols}

$\mathbf{i}_{t} \quad$ normalized instantaneous current vector

$i_{L 1, t} \quad$ instantaneous current in the phase L1

$i_{L 2, t} \quad$ instantaneous current in the phase L2

$i_{L 3, t} \quad$ instantaneous current in the phase L3

$\underline{i}_{S} \quad$ space vector of the current in the $\alpha \beta$-plane

$\underline{i}_{S, d q} \quad$ space vector of the current in the dq-plane

$i_{S, d_{1+}} \quad$ direct/active, positive-sequence component of the normalized output space vector of the current

$i_{S, q_{1+}} \quad$ quadrature/reactive, positive-sequence component of the normalized output space vector of the current

$i_{S, d_{1+}, r e f}$ reference value of the direct/active, positive-sequence component of the normalized space vector of

the current

$i_{S, q_{1}, \text { ref }}$ reference value of the quadrature/reactive, positive-sequence component of the normalized space

$i_{S, q_{1+}, r e f}$ vector of the current

$\mathbf{u}_{N, t} \quad$ normalized phase-to-neutral instantaneous voltage vector

$\mathbf{u}_{N, t, r e f}$ normalized phase-to-neutral instantaneous reference voltage vector

$u_{1 N, t} \quad$ normalized phase-to-neutral instantaneous voltage in the phase L1

$u_{2 N, t} \quad$ normalized phase-to-neutral instantaneous voltage in the phase L2

$u_{3 N, t} \quad$ normalized phase-to-neutral instantaneous voltage in the phase L3

$\underline{u}_{S, d q} \quad$ normalized voltage space vector in the dq-plane

$\mathbf{U}$ root-mean-square value of the phase-to-phase voltage vector

$U_{n} \quad$ nominal phase-to-phase voltage

u normalized phase-to-phase voltage vector

$u_{12}$ root-mean-square value of the normalized phase-to-phase voltage between the phases L1-L2

$u_{23} \quad$ root-mean-square value of the normalized phase-to-phase voltage between the phases L2-L3

$u_{31} \quad$ root-mean-square value of the normalized phase-to-phase voltage between the phases L1-L3

$u_{S, d_{1+}} \quad$ direct/active, positive-sequence component of the normalized output space vector of the voltage

$u_{S, q_{1+}}$ quadrature/reactive, positive-sequence component of the normalized output space vector of the voltage

$u_{S, d_{1+}, \text { ref }} \begin{aligned} & \text { reference value of the } \\ & \text { vector of the voltage }\end{aligned}$

$u_{S, q_{1+}, r e f}$ reference value of the quadrature/reactive, positive-sequence component of the normalized output

space vector of the voltage

$\underline{u}_{1+} \quad$ complex, normalized value of the positive-sequence voltage

$u_{1+} \quad$ normalized magnitude of the positive-sequence voltage

$\theta \quad$ angle of the positive-sequence voltage

$U_{D C L} \quad$ DC-link voltage

$u_{L C 1 N, t}$ instantaneous value of the phase-to-neutral voltage in the phase L1 at the inverter output

$u_{L C 2 N, t}$ instantaneous value of the phase-to-neutral voltage in the phase L2 at the inverter output

$u_{L C 3 N, t}$ instantaneous value of the phase-to-neutral voltage in the phase L3 at the inverter output

$P_{D E R} \quad$ power infeed of wind turbines 
$P_{L O A D} \quad$ power consumption of loads

$P \quad$ electrical power of the converter

$p \quad$ normalized active power output of the converter

$q$ normalized reactive power output of the converter

$p_{\text {ref }} \quad$ reference value of the active power

$q_{\text {ref }} \quad$ reference value of the reactive power

$\omega \quad$ angular frequency

$\omega_{n} \quad$ nominal angular frequency

$L \quad$ inductance of the output filter of the converter

$l$ normalized inductance of the output filter of the converter

$R \quad$ resistance of the output filter of the converter

C capacitance of the output filter of the converter

c normalized capacitance of the output filter of the converter

$\tau_{i} \quad$ time constant of the current control loop

$K_{I, P} \quad$ proportional controller gain of the current control loop

$K_{I, I} \quad$ integral gain of the current control loop

$K_{U, P} \quad$ proportional gain of the voltage control loop

$K_{U, I} \quad$ integral gain of the voltage control loop

$S_{n} \quad$ nominal apparent power of the converter

$\Phi_{R} \quad$ phase margin of the converter control

$p_{t} \quad$ instantaneous active power

$q_{t} \quad$ instantaneous reactive power

$u_{C} \quad$ normalized voltage at the PCC of the converter

$u_{\text {load }} \quad$ normalized voltage at the connection point of the load

$R_{l 1}^{\prime} \quad$ length-related resistance of line 1

$X_{l 1}^{\prime} \quad$ length-related reactance of line 1

$R_{l 2}^{\prime} \quad$ length-related resistance of line 2

$X_{l 2}^{\prime} \quad$ length-related reactance of line 2

$u_{k} \quad$ short circuit voltage of the converter transformer

$P_{k} \quad$ short circuit power of the converter transformer

$n \quad$ number of converters connected in parallel

$f_{I L 1} \quad$ switching signal for the switch $S_{I L 1}$

$f_{I L 2} \quad$ switching signal for the switch $S_{I L 2}$

$f_{I L 3} \quad$ switching signal for the switch $S_{I L 3}$

$f_{I L 1}^{\prime} \quad$ switching signal for the switch $S_{I L 1}^{\prime}$

$f_{I L 2}^{\prime} \quad$ switching signal for the switch $S_{I L 2}^{\prime}$

$f_{I L 3}^{\prime} \quad$ switching signal for the switch $S_{I L 3}^{\prime}$

\section{References}

1. Fraunhofer IWES. The European Power System in 2030: Flexibility Challenges and Integration Benefits. An Analysis with a Focus on the Pentalateral Energy Forum Region. Analysis on Behalf of Agora Energiewende. 2015. Available online: https://www.agora-energiewende.de/fileadmin2/Projekte/2014/Ein-flexiblerStrommarkt-2030/Agora_European_Flexibility_Challenges_Integration_Benefits_WEB_Rev1.pdf (accessed on 23 June 2020).

2. IRENA. Renewable Energy Prospects for the European Union. In International Renewable Energy Agency (IRENA); European Commission (EC): Abu Dhabi, UAE, 2018. Available online: https://www.irena.org/ publications / 2018/Feb/Renewable-energy-prospects-for-the-EU (accessed on 23 June 2020).

3. Sterner, M.; Stadler, I. Handbook of Energy Storage: Demand, Technologies, Integration; Springer: Berlin/Heidelberg, Germany, 2019.

4. Marnay, C.; Chatzivasileiadis, S.; Abbey, C.; Iravani, R.; Joos, G.; Lombardi, P.; Mancarella, P.; von Appen, J. Microgrid evolution roadmap. In Proceedings of the 2015 International Symposium on Smart Electric Distribution Systems and Technologies (EDST), Vienna, Austria, 8-11 September 2015; pp. 139-144.

5. Mahmoud, M.S. Microgrid: Advanced Control Methods and Renewable Energy System Integration; Elsevier: Amsterdam, The Netherlands, 2016.

6. Tabatabaei, N.M.; Kabalci, E.; Bizon, N. Microgrid Architectures, Control and Protection Methods; Springer: Berlin/Heidelberg, Germany, 2019. 
7. Roggatz, C.; Power, M.; Singh, N. Power System Restoration: Meeting the Challenge to Resiliency from Distributed Generation. IEEE Power Energy Mag. 2020, 18, 31-40. [CrossRef]

8. Zhao, B.; Zhang, X.; Li, P.; Wang, K.; Xue, M.; Wang, C. Optimal sizing, operating strategy and operational experience of a stand-alone microgrid on Dongfushan Island. Appl. Energy 2014, 113, 1656-1666. [CrossRef]

9. Katiraei, F.; Iravani, M.R. Power management strategies for a microgrid with multiple distributed generation units. IEEE Trans. Power Syst. 2006, 21, 1821-1831. [CrossRef]

10. Barklund, E.; Pogaku, N.; Prodanovic, M.; Hernandez-Aramburo, C.; Green, T.C. Energy management in autonomous microgrid using stability-constrained droop control of inverters. IEEE Trans. Power Electron. 2008, 23, 2346-2352. [CrossRef]

11. Peng, Z.; Wang, J.; Bi, D.; Wen, Y.; Dai, Y.; Yin, X.; Shen, Z.J. Droop control strategy incorporating coupling compensation and virtual impedance for microgrid application. IEEE Trans. Energy Convers. 2019, 34, 277-291. [CrossRef]

12. Han, H.; Liu, Y.; Sun, Y.; Su, M.; Guerrero, J.M. An improved droop control strategy for reactive power sharing in islanded microgrid. IEEE Trans. Power Electron. 2014, 30, 3133-3141. [CrossRef]

13. Garde, R.; Casado, S.; Santamaria, M.; Aguado, M. Power quality and stability analysis during islanded mode operation in a microgrid based on master-slave configuration. In Proceedings of the 2015 Saudi Arabia Smart Grid (SASG), Jeddah, Saudi Arabia, 7-9 December 2015; pp. 1-8.

14. Talapur, G.G.; Suryawanshi, H.M.; Shitole, A.B.; Nachankar, P. Combined Droop and Master-Slave Method for Load Sharing in Stand-alone AC Microgrid. In Proceedings of the IECON 2018-44th Annual Conference of the IEEE Industrial Electronics Society, Washington, DC, USA, 21-23 October 2018; pp. 1705-1710.

15. Verma, V.; Talpur, G.G. Decentralized master-slave operation of microgrid using current controlled distributed generation sources. In Proceedings of the 2012 IEEE International Conference on Power Electronics, Drives and Energy Systems (PEDES), Bengaluru, India, 16-19 December 2012; pp. 1-6.

16. Caldognetto, T.; Tenti, P. Microgrids operation based on master-slave cooperative control. IEEE J. Emerg. Sel. Top. Power Electron. 2014, 2, 1081-1088. [CrossRef]

17. Divakaran, A.M.; Hamilton, D.; Manjunatha, K.N.; Minakshi, M. Design, development and thermal analysis of reusable Li-ion battery module for future mobile and stationary applications. Energies 2020, 13, 1477. [CrossRef]

18. Friend, F. Cold load pickup issues. In Proceedings of the 2009 62nd Annual Conference for Protective Relay Engineers, Austin, TX, USA, 30 March-2 April 2009; pp. 176-187.

19. E-Control. Technische und organisatorische Regeln für Betreiber und Benutzer von Netzen: TOR Erzeuger: Anschluss und Parallelbetrieb von Stromerzeugungsanlagen des Typs B. 2019. Available online: https:/ / www.e-control.at/ documents/1785851/1811582/TOR+Erzeuger+Typ+B+V1.0. pdf/a9a7e5ae-5842-caa9-d2c0-93be4b6e0802?t=1562757801048 (accessed on 23 June 2020).

20. SMA. Design of Off-Grid Systems with Sunny Island 4.4M/6.0H/8.0H Devices. 2020. Available online: https:/ / files.sma.de/downloads/Designing-OffGridSystem-PL-en-24.pdf (accessed on 23 June 2020).

21. Marchgraber, J.; Gawlik, W. Dynamic Voltage Support of Converters during Grid Faults in Accordance with National Grid Code Requirements. Energies 2020, 13, 2484. [CrossRef]

22. Marchgraber, J.; Alács, C.; Guo, Y.; Gawlik, W.; Anta, A.; Stimmer, A.; Lenz, M.; Froschauer, M.; Leonhardt, M. Comparison of Control Strategies to Realize Synthetic Inertia in Converters. Energies 2020, 13, 3491. [CrossRef]

23. Henninger, S. Netzdienliche Integration Regenerativer Energiequellen über Stromrichtergekoppelte Einspeisenetze mit Integrierten Energiespeichern. Ph.D. Thesis, FAU Erlangen, Erlangen, Germany, 2019.

24. Yazdani, A.; Iravani, R. Voltage-Sourced Converters in Power Systems: Modeling, Control, and Applications; John Wiley \& Sons: Hoboken, NJ, USA, 2010.

25. Wurm, M.; Jonke, P.; Marchgraber, J.; Gawlik, W.; Vitovec, W. Ortsnetz-Inselbetriebsversuch mit einem 2,5-MVA/2,2-MWh-Batteriespeicher: Messergebnisse und Vergleich mit einem Controller Hardware-in-the-loop Setup. E I Elektrotechnik Und Informationstechnik 2019, 136, 368-376. [CrossRef] 
26. Bagert, M. Elektrischer Eigenbedarf: Elektrotechnik in Kraftwerken und Industrie, Zusammenwirken von Kraftwerken und Netzen, Beispiele Ausgeführter Anlagen; VDE Verlag: Berlin, Germany, 2012.

27. Marchgraber, J.; Alács, C.; Nemec-Begluk, S.; Gawlik, W.; Jonke, P.; Wurm, M.; Wailzer, G.; Vitovec, W. Schwarzstart und Inselbetrieb eines Netzabschnitts mit Windenergieeinspeisung mithilfe eines Batteriespeichers. In Proceedings of the 11th Internationale Energiewirtschaftstagung, Vienna, Austria, 13-15 February 2019.

(c)

(C) 2020 by the authors. Licensee MDPI, Basel, Switzerland. This article is an open access article distributed under the terms and conditions of the Creative Commons Attribution (CC BY) license (http:/ / creativecommons.org/licenses/by/4.0/). 